\title{
Environmental niche separation promotes coexistence among ecologically similar zooplankton species-North Sea copepods as a case study
}

\author{
Lindegren, Martin ; Thomas, Mridul K.; Jónasdóttir, Sigrún H.; Nielsen, Torkel Gissel; Munk, Peter
}

Published in:

Limnology and Oceanography

Link to article, DOI:

10.1002/Ino.11322

Publication date:

2020

Document Version

Peer reviewed version

Link back to DTU Orbit

Citation $(A P A)$ :

Lindegren, M., Thomas, M. K., Jónasdóttir, S. H., Nielsen, T. G., \& Munk, P. (2020). Environmental niche separation promotes coexistence among ecologically similar zooplankton species-North Sea copepods as a case study. Limnology and Oceanography, 65(3), 545-556. https://doi.org/10.1002//no.11322

\section{General rights}

Copyright and moral rights for the publications made accessible in the public portal are retained by the authors and/or other copyright owners and it is a condition of accessing publications that users recognise and abide by the legal requirements associated with these rights.

- Users may download and print one copy of any publication from the public portal for the purpose of private study or research.

- You may not further distribute the material or use it for any profit-making activity or commercial gain

- You may freely distribute the URL identifying the publication in the public portal 
1 Environmental niche separation promotes coexistence among ecologically similar zooplankton species - North Sea copepods as a case study

4 Authors: Martin Lindegren ${ }^{1 *}$, Mridul K. Thomas ${ }^{1}$, Sigrún H. Jónasdóttir ${ }^{2}$, Torkel Gissel Nielsen², 5 Peter Munk ${ }^{2}$

6 Affiliations: ${ }^{1}$ Centre for Ocean Life, and ${ }^{2}$ Section of Oceans and Arctic, National Institute of

7 Aquatic Resources, Technical University of Denmark, Kemitorvet Bygning 202, 2800 Kgs.

8 Lyngby, Denmark.

Abstract

11 Marine zooplankton are among the most diverse and abundant organisms on earth. Despite a great wealth of knowledge and research on their ecology, the processes promoting co-existence and maintaining their high diversity worldwide are poorly known. In order to understand the processes underpinning coexistence among marine zooplankton, we investigated the existence and degree of niche separation within two pairs of taxonomically and ecologically related species of copepods belonging to the widespread, abundant genera Calanus and Oithona. We compared the spatial variation in species abundances to the abiotic and biotic environment using a multi-model approach and vertically resolved survey data on zooplankton composition, abundances and environmental conditions in the North Sea. Our results demonstrate pronounced spatial differences between species in each pair, primarily in their vertical abundance distributions. These differences can largely be explained by different preferences for temperature and salinity. This supports the occurrence of environmental niche separation in marine zooplankton and highlights its role as a mechanism reducing inter-specific competition and promoting coexistence. 


\section{Introduction}

Niche separation (or the analogous terms niche segregation and niche differentiation) is commonly regarded as the key process favouring coexistence among ecologically and functionally similar species of plants and animals (MacArthur 1958; Pianka 1974; Ben-David et al. 1996; Silvertown 2004; Angert et al. 2009). It therefore contributes to the process of speciation and the maintenance of biodiversity at large (Chesson 2000). Niche separation generally occurs through a reduction in competition for limiting resources or living space, which, if left unresolved would inevitably lead to the competitive exclusion of weaker competitors and a loss of biodiversity (Hardin 1960). The ways in which species can reduce inter-specific competition are numerous (e.g. consuming different foods, or using different parts of the physical environment) but all serve to modify the resource requirements of competing species so as to reduce, or minimize overlap between their fundamental niches (Hutchinson 1957).

Although conceptually well-understood, investigating niche separation in the field is challenging, 1 primarily due to the long time-scales over which natural selection and niche separation occurs. Instead, we typically have to resort to studying what is sometimes termed "the ghost of competition past” (Connell 1980), the evolutionary end-result of competitive exclusion and niche separation. This end-result is often manifested in slight but important differences in the niches of closely related and competing species, for instance in terms of their diet requirements, the type of predators they are exposed (and adapted) to, as well as their preferences for certain physical habitats (MacArthur 1958; Crowder 1986; Steiner et al. 2007; Wilson et al. 2015). Alternatively, niche separation may be studied by investigating short-term responses of natural communities to invasive 9 species (Mooney and Cleland 2001; Mack et al. 2000; Lindegren et al. 2012), leading to either local 
extinction through competitive exclusion, or coexistence mediated through adaptation (behavioural, morphological or physiological).

Marine zooplankton constitute among the most diverse, abundant and ecologically important organisms on earth (Verity and Smetacek 1996), directly or indirectly contributing to maintaining key ecosystem functions and services essential for human well-being. These services include for instance food provisioning by acting as key prey for many commercially important fish species worldwide and climate regulation by affecting carbon sequestration through increased downward flux of organic matter via excretion and respiration at depth (Ducklow et al. 2001; Steinberg et al. 2002; Jónasdóttir et al. 2015; Visser et al. 2017). Among marine zooplankton, copepods are a dominant and generally well-studied group of organisms, especially in terms of their physiology (e.g. rates of consumption, respiration and metabolism), behaviour (e.g. modes of feeding, mating and predator avoidance) and their role in marine food webs as both predators of phytoplankton and prey for higher trophic level predators (Möllmann et al. 2003; Lindegren et al. 2011; Blenckner et al. 2015). However, the underlying processes promoting co-existence and maintaining their high diversity worldwide are largely understudied with relatively few related examples from the marine literature (e.g. Poulet 1978; Katechakis et al. 2004; Helaouet and Beaugrand 2007). The marine copepods Calanus finmarchicus, Calanus helgolandicus, Oithona atlantica and Oithona similis represent two pairs of widespread and ecologically important zooplankton species in the North Atlantic. Despite their high abundances the Oithona species are largely understudied (Galliene 2001) and often excluded from comparative studies (McGinty et al. 2018), primarily due to undersampling by most standard zooplankton sampling methods. In contrast, the Calanus species are very well studied and have attracted considerable attention in the literature (Bonnet et al. 
2005; Helaouet and Beaugrand 2007; Jónasdóttir and Koski 2011; Melle et al. 2014). Both pairs coexist in the North Sea despite large similarities in the morphological, physiological and behavioural traits within each genus (Fleminger and Hulsemann 1977; Bucklin et al. 1995). C. finmarchicus and $C$. helgolandicus are large ( $>2 \mathrm{~mm})$, filter-current feeding copepods that in the North Sea constitute key prey for early-life stages and adults of commercially important fish species, e.g. the Atlantic cod (Beugrand et al. 2003) and Lesser sandeel (VanDeurs et al. 2009). The Oithona species are considerably smaller $(\sim 0.5 \mathrm{~mm})$ ambush feeders on ciliates, detritus and phytoplankton. Consequently, they are thought to serve as an important link of energy from primary producers to fish larvae (Nielsen and Sabatini 1996). Interestingly, these copepod species show pronounced temporal fluctuations and long-term shifts in their relative dominance, particularly between C. finmarchicus and C. helgolandicus. These shifts have been related to pronounced changes in hydrographic conditions, linked to the Atlantic Multi-decadal Oscillation (Beaugrand 2009). This suggests that closely related species may exhibit opposite affinities for and responses to environmental conditions (Bonnet et al. 2005; Beaugrand 2009; Helaouet and Beaugrand 2007;

Wilson et al. 2016). Although characterized by different temporal dynamics, as well as biogeography in the Northern Atlantic, the North Sea constitutes a key area for all these species where they co-occur in high abundances.

In order to understand the processes favouring coexistence among marine zooplankton in general and copepods in particular, we investigated the degree of niche separation using the two abovementioned pairs of highly abundant and widely distributed Calanus and Oithona species in the North Sea as a case study. Our approach is to identify and quantify differences in habitat preferences and resource use that we assume originated as a result of niche separation in response to 
past competition. We hypothesize that any spatial differences in their abundance distributions are due to different responses to the same set of underlying drivers.

\section{Material and methods}

\section{Study area and data collection}

Sampling was carried out along transects in three areas of the North Sea (Fig. 1; Fig. S1): a)

Transect A (Dogger bank) covered stations from the deep central North Sea up along the flanks of Dogger Bank. The transect was sampled for 4 years; 13 August 2002 (2 stations), 19 August 2003 (3 stations), 28 July- 2 August 2005 (4 stations) and 5-7 September 2007 (12 stations), b) Transect B (Buchan) was sampled 8-9 September 2007 and consisted of 10 stations from coast off Buchan towards deeper areas, and c) Transect C (Hanstholm) was positioned in the eastern North Sea, off the Danish coast, with 6 stations sampled 6-7 May 1997 and 8 stations sampled 11-12 September 2007. At each station, hydrographic profiles of temperature, salinity, fluorescence, oxygen and irradiance were measured from surface to $400 \mathrm{~m}$ depth or to $5 \mathrm{~m}$ above the bottom by a Seabird SBE11 (9+) CTD, with mounted Biospherical QSP-2300L PAR Sensor, SBE 43 Dissolved Oxygen Sensor, and Turner Cyclops-7 Fluorometer. Following the CTD cast zooplankton were sampled. In 2007 the sampling was carried out using a $0.25 \mathrm{~m}^{2}$ opening-closing net (Multinet ${ }^{\circledR}$ ). The gear was lowered to 5-10 m above bottom and subsequently towed vertically, opening five 53 micron meshed nets at every $10 \mathrm{~m}$ to the surface. When depth was more than $50 \mathrm{~m}$, a consecutive haul was carried out at same position to avail samples from all possible 10 meter strata towards the bottom. In 1997, 2002, 2003 and 2005 zooplankton was sampled with a submersible pump. The water was pumped directly into an attached $30 \mu \mathrm{m}$ plankton net protected by an outer $200 \mu \mathrm{m}$ mesh net bag. The submersible pump (Homa, H-500, with the plankton net fitted to the outlet) was lowered to a predetermined depth and turned on (flow $1.2 \mathrm{~m}^{3} \mathrm{~min}^{-1}$ ). In 1997 it was raised within 10 to $20 \mathrm{~m}$ wide 
121 depth strata before turned off, while it the other years sampled for 3 minutes at depth. In 2002 122 samples were taken at $10 \mathrm{~m}$ depth intervals, while at $5 \mathrm{~m}$ intervals in 2003 and 2005. The nets were 123 washed, contents transferred to containers and every sample preserved in $4 \%$ borax buffered 124 formaldehyde. In the laboratory each sample was subsampled to different degrees, and from each 125 subsample the zooplankton were enumerated, identified to lowest taxonomic levels and length 126 measured, copepods to their cephalothorax lengths. While the sampling gear was not the same 127 during all cruises, the difference should not affect the analysis in this study. The comparisons are done between species sampled with the same gear at the same time. Additionally, the mesh sizes in 129 both sampling devices were fine (30 and $53 \mu \mathrm{m}$ ) to successfully capture the smaller Oithona, and the 130 volume filtered was well monitored for both devices minimizing error in estimates between devices.

\section{Statistical analysis}

133 Three complementary statistical tools were used to examine and compare the spatial distribution patterns of species abundances in relation to a number of drivers, representing their environmental niches in terms of: (i) temperature, (ii) salinity, (iii) Chlorophyll a (chl a; a proxy for food concentration); (iv) and the intensity of photosynthetically active radiation (PAR; a proxy for predation risk), each measured at any given transect, station, depth and time. In addition, transect and life-stage were included as factors in the analyses to account for any differences in the mean abundances between areas and between adult males, females and juveniles (copepodites) that cannot be attributed to the environmental conditions. The same set of explanatory variables was used as covariates across species and statistical analyses, including: (i) Generalized Additive 142 Models (GAMs), (ii) random forests (RFs); (iii) and gradient boosting machines (GBMs). All 143 variables had a Variance Inflation Factor (VIF) $<3$, indicating a negligible degree of collinearity 144 between predictors. After model fitting the resulting statistical relationships and derived response 
curves between species abundances and the environmental variables, as well as the relative importance among these drivers were compared across methods to assess the sensitivity and robustness of the results and the characterization of species niches to the choice of methodology. Furthermore, we performed a k-fold cross validation analysis (Picard and Cook 1984) to enable a formal comparison of prediction skill across methods by fitting the set of models to randomly selected subsets of the data (amounting to $75 \%$ of the observations). We then assessed the predictive accuracy of each model by comparing the observed values with the predicted estimates for the remaining test data sets for each species. The cross-validation analysis was repeated 100 times (each time with a new random and serially independent draw) in order to assess the range of uncertainty associated with the predictions (i.e., reflected by the mean square errors (MSE) of model predictions. All statistical analyses were conducted using the R software, version 3.1.2 (R core Team 2012) using the following packages: “mgcv” (Wood 2017), “randomForest” (Liaw and Wiener 2002) and “gbm” (Greenwell et al. 2018).

\section{Generalized Additive Models}

Generalized Additive Models (GAMs; Hastie and Tibshirani 1990; Wood 2017) provide a suitable and commonly used tool to examine non-linear dependencies in ecological data. The following formulations with natural log-transformed species abundance estimates as responses were used: $\log (N)=a+s($ Temperature $)+s($ Salinity $)+s(\log ($ Chl a $))+s(\log (P A R))+$ transect + stage $+e$ where $a$ is the intercept, $s$ the thin plate smoothing function and $\varepsilon$ the error term. Although the number of regression splines is optimized (and penalized) by the generalized cross validation criterion (GCV), the degrees of freedom of the spline smoother function (s) was further constrained 
to three knots $(\mathrm{k}=3)$ to allow for potential nonlinearities, but restrict flexibility during model fitting. Finally, we applied backwards model selection based on the GCV and partial F-tests to identify the best possible set of predictors.

\section{Random forests}

Random forests (RFs) are a machine learning tool comprising ensembles of decision trees that rely on bagging (i.e. bootstrap aggregation). They are used for both regression (as in our study) and classification problems (Breiman 2002). Individual regression trees within the random forest are trained on randomly selected subsets of the data. In each tree, the data is recursively partitioned, at each instance (i.e. node) based on the most strongly associated predictor. At each node in a tree, a random subset of predictors is evaluated for partitioning. The final tree prediction is given by the average value of the data within each branch of the tree. The final forest prediction is obtained by averaging predictions across all trees in the forest. RFs are capable of reproducing complex nonlinear shapes in single and multiple dimensions, making them suitable for ecological applications in which complex shapes are to be expected. In our study, we used the fitted RFs to estimate the nonlinear partial effects of individual variables, which are obtained by averaging out the effects of all other predictors on the quantity of interest. We predicted log(abundance) with all other variables used in the GAM model above. However, the random forest has fewer constraints and is able to capture interactions between variables that cannot easily be achieved with additive models.

\section{Gradient boosting machines}

Gradient boosting machines (GBMs) are a machine learning tool that we use here with decision trees (though they may be constructed with other types of models) (Freund and Schapire 1997; 
Friendman 2001). When used with decision trees, they differ from RFs primarily in using boosting as an ensemble technique instead of bagging. Unlike the bootstrap-based bagging method, boosting works sequentially. Individual decision trees are fit to the residuals of the previous tree till a stopping criterion is reached (to prevent overfitting). Due in part to this sequential nature, GBMs are more sensitive to overfitting problems than RFs but may achieve higher performance.

\section{Results}

The species demonstrate distinct vertical distribution patterns, where $C$. finmarchicus and $O$. atlantica show higher abundances at lower depths (below 45 meters) while C. helgolandicus is more evenly distributed throughout the water column and $O$. similis shows a clear preference for surface waters (Fig. 2; Fig. S1-S2). The averaged vertical distribution patterns are largely consistent across life-stages (Fig. S2), except for lower abundances of $C$. helgolandicus juveniles (copepodites) in surface waters compared to adults (divided into males and females), and vice versa for O. atlantica. Temperature and salinity were strong abiotic predictors of abundances in all species and methods, illustrated by their high variable importance scores based on RFs and GBMs (Table 1). In addition, Chl $a$ proved to be a good predictor. In contrast, PAR had low importance scores and was found to be statistically insignificant in the GAMs. It was therefore excluded during model selection and was omitted as a predictor in the final GAMs (Table S1-S5). In addition to these predictors, the factors transect and life-stage were significant and generally of high relative importance for all species (Table 1; Table S2-S5). The different intercepts highlights regional variability in mean log(abundance) between different areas of the North Sea, as well as between juveniles and adults (separated into males and females) (Fig. S1-S2). Although interesting in its own right, these differences primarily reflect well-known population demographics (i.e., higher number of juveniles compared to adults) and sex specific mortality rates (i.e., higher predation 
mortalities on males compared to females), giving rise to a skewed sex ratio among copepods (Hirst et al., 2010). Since the primary focus of this study is on potential differences in environmental niches among closely related species we will not discuss and further elaborate on the underlying mechanisms explaining differences in abundances within each species related to these factors. The methods explained a high degree of observed variances in log(abundance) across species, ranging from 36\% (C. helgolandicus) to 78\% (O. similis) (Table S2), with RFs generally outperforming GAMs and GBMs in terms of explained variance and mean squared errors of model predictions on test data not included during fitting/training (Fig. 3). Finally, standard model diagnostics for the GAMs demonstrate normally distributed residuals for all species (Fig. S3-S6).

The differences in the spatial abundance distributions between species are reflected by different responses to the identified drivers, largely representing their environmental niches in terms of temperature and salinity. In terms of temperature, C. finmarchicus and $C$. helgolandicus both demonstrate non-linear response curves that are roughly hump-shaped (Fig. 4a). The patterns are fairly consistent across methods, but with RFs and GBMs suggesting a more pronounced affinity of C. finmarchicus for colder water than that identified using GAMs (Fig. 2b). The Oithona species also demonstrate different responses to temperature that are identified consistently across methods, 234 illustrated by a generally positive saturating relationship of $O$. similis compared to a declining temperature response of $O$. atlantica (Fig. 4c, d). In terms of salinity, different responses between species in each genus are also evident, characterized by non-linear increasing and decreasing relationships for $C$. finmarchicus and $C$. helgolandicus, respectively (Fig. 5a, b). Likewise, $O$. atlantica and $O$. similis show opposite salinity responses (Fig. 5c, d), indicating an affinity for high and low salinities respectively. In contrast to temperature and salinity, all species seem to respond in the same way to our proxy for food availability, illustrated by a similar positive linear response to 
241 Chl $a$ (Fig. 6). The response curves are consistent across methods, except for $C$. finmarchicus and 242 C. helgolandicus where the GAMs show no statistically significant relationship (Fig. 6a). In order 243 to summarize the responses of the species to the entire set of environmental drivers we 244 characterized the environmental niches of the species based on GAM predictions of $245 \log$ (abundances) across the entire range of observed temperature, salinity and Chl $a$ values. The 246 model predictions show clear differences in the environmental niches of species within the same 247 genera. This is illustrated by limited overlap of predicted $\log$ (abundances) in a 3-D niche space 248 represented by temperature, salinity and Chl $a$ (Fig. 7). In general, C. finmarchicus and O. atlantica 249 prevail at low temperatures and high salinities and vice versa for $C$. helgolandicus and $O$. similis.

\section{Discussion}

252 Niche separation is a key process reducing inter-specific competition and thereby facilitating coexistence and the maintenance of biodiversity at large (MacArthur 1958; Pianka 1974; Chesson 2000; Silvertown 2004). On the basis of vertically resolved survey data and three complementary statistical approaches we have demonstrated pronounced and methodologically robust differences in environmental niches in two pairs of closely related species of marine copepods. Both pairs coexist in the North Sea, despite large similarities in their morphological, physiological and behavioural traits (Fleminger and Hulsemann 1977; Bucklin et al. 1995). The niche separation could largely be explained by different responses of the species within each genus to temperature and salinity.

The different responses to temperature highlight a separation between species adapted to colder or warmer waters. This is typically reflected by distinct biogeographic patterns characterized by either

263 a sub-arctic or a boreal distribution, as has been shown for $C$. finmarchicus and $C$. helgolandicus in 264 the North Atlantic (Bonnet et al. 2005; Helaouet and Beaugrand 2007). However, species may not 
only differentiate across latitude and longitude but also separate in terms of their vertical distributions. The North Sea is highly stratified, especially during summer when high temperatures and low wind stress supress mixing and promote a vertical separation of water masses with markedly different physical properties (Nielsen et al. 1993). The vertical separation of water masses is mirrored in the abundance distributions of $O$. atlantica and $O$. similis showing different preferences for deeper and shallow waters, respectively. This is turn is reflected by their opposite temperature responses with peak abundances observed at either the cold or warm end of the temperature range. In contrast to Oithona, the Calanus species demonstrate a less pronounced vertical separation of abundances, but with $C$. finmarchicus generally preferring deeper waters compared to a more uniform depth distribution of $C$. helgolandicus. The lower degree of vertical separation among Calanus is reflected by more similar temperature response for both species. However, their humped-shaped response curves differ in terms of their optima and spread. This is highlighted by a preference for warmer temperatures within a rather narrow temperature range for C. helgolandicus and a broader temperature range with a preference for colder temperatures for $C$. finmarchicus. The derived thermal niches support previous observational studies and reviews 280 demonstrating peak abundances of $C$. helgolandicus and $C$. finmarchicus at temperatures $=>13^{\circ} \mathrm{C}$ 281 and $<10^{\circ} \mathrm{C}$, respectively (Bonnet et al. 2005; Helaouet and Beaugrand 2007; Jónasdóttir and Koski 2011; Melle et al. 2014; McGinty et al. 2018) and corresponds well to available meta-analysis across zooplankton taxa showing a general concave relationship with temperature (Forster et al. 2011). The broader temperature range of $C$. finmarchicus allows it to tolerate a larger range of environments and consequently occupy a considerably larger distribution area, as evidenced by its widespread biogeography across the North Atlantic (Helaouet and Beaugrand 2007; Melle et al. 2014). The different temperature responses likely reflect different thermal tolerances of species within each genus, although the link between physiological tolerance and abundance is complicated 
by the influences of resource availability, interactions with other species, and density-dependent processes. Furthermore, it should be noted that the vertical distributions presented here are based primarily on summer samples (July-September). This is the period when C. finmarchicus is preparing for overwintering by accumulating lipids and initiating a descent to deeper waters (Johnson et al. 2008; Melle et al. 2014; Krumhansl et al. 2018). Hence, onset of diapause could contribute to the deeper distribution of the species and partly explain the affinity of $C$. finmarchicus for lower temperatures. However, Jónasdóttir and Koski (2011) demonstrated that females of the same North Sea population were still reproductively active and feeding in the deeper cooler waters during July-August. Hence, we believe that the influence of diapause on the derived thermal response of $C$. finmarchicus is relatively marginal.

In contrast to temperature, the pronounced differences in the species responses to salinity are more difficult to explain by any direct physiological processes. Physiological effects of salinity has been demonstrated in the neighbouring, brackish Baltic Sea, where the low salinities have been shown to critically affect survival and reproduction of copepods, notably Pseudocalanus acuspes (Möllmann et al. 2003). However, the narrow range of salinities observed in this study (i.e. 34.7 to 35.2 PSU) are well above the levels where salinity has any direct effect on reproduction. Instead, the opposite responses to salinity demonstrated within both genera is likely related to the different geographical origins of the water masses in this region (i.e. either Atlantic or coastal). Inflows of high salinity and oxygen rich water from the Atlantic constitute the primary vector not only for nutrients

309 (Winther and Johanessen 2006) but also for passively drifting biota from source populations outside the North Sea, including $C$. finmarchicus. This species advects into the North Sea from the north

311 after re-emerging from winter hibernation at great depths (Heath et al. 1999; Reid et al. 2003). Hence, the positive salinity response of $C$. finmarchicus may largely reflect its Atlantic origin. 
313 Whether a similar transport process can explain also the positive salinity response of $O$. atlantica is 314 unclear and merit further attention. In contrast to these species, C. helgolandicus and $O$. similis 315 show a clear preference for water masses with lower salinity. These water masses primarily 316 originate from coastal areas influenced by freshwater discharge from rivers (e.g. Rhine) and the 317 outflow from the brackish Baltic Sea. Due to the lower salinity (and higher temperatures) these 318 lighter water masses overlay the denser, saline and colder source water of more Atlantic origin. This 319 in turn may explain the more shallow distribution and high abundances of particularly O. similis 320 closer to the surface.

Species may not only reduce competition by occupying different physical environments but also by shifting in opposite directions along a trade-off curve, such as that between maximizing foraging levels of both prey and predators. Despite different vertical distributions and affinities for temperature and salinity all species show the same positive response of abundances to Chl $a$. This indicates that all species concentrate (either by active movement or passive dispersal) and/or perform better (i.e., in terms of higher egg production) in patches with high food availability, as has previously been demonstrated for both Calanus and Oithona (Sabatini and Kiørboe 1994; Bonnet et al. 2005; Ward and Hirst 2007; Melle et al., 2014). Consequently, differences in depth distribution or environmental affinities does not necessarily reflect different priorities of the species in terms of maximizing foraging opportunities. Nor does it reflect differences in feeding behaviour, since species within each genus share the same feeding mode, i.e. either active, feeding current feeders 334 (Calanus) or passive, ambush feeders (Oithona). However, the differences in depth distribution may reflect different prey preferences, for instance for different sized prey with distinct vertical distributions, that are not captured by our crude proxy for food availability. Understanding such 
differences in food availability and feeding preferences may shed light on the role and relative importance of niche separation in terms of both food and the physical environment and the way in which these differences determine the distribution and coexistence of species. One prominent example is the clear niche separation between the ecologically similar species of sardine and anchovy that coexist in upwelling areas around the world (Schwartzlose et al. 1999). Their niche separation is manifested not only by different affinities for the physical environment (Takasuka et al. 2007; Rykazewski and Checkley 2008; Lindegren et al. 2013) but also in terms of their adaptations and preferences for food of different sizes (Van der Lingen et al. 2006).

Investment in foraging generally trades off against mortality, as higher feeding activity typically increases exposure to potential predators. To minimize the risk of mortality, individuals may select for habitats reducing predator exposure. For small planktonic organisms the primary behavioural response is to avoid habitats with high light intensity where the probability of detection, at least by visual predators, such as fish is increased. Although these trade-offs and mechanisms likely apply also to our study species, the model results show no effect of light on the abundance distribution of any of the species. This lack of statistical signal may point towards PAR being a poor proxy for predation risk, as it does not represent the abundance of potential predators present in the area during the time of sampling. However, light intensity has been shown to be a strong environmental cue inducing various predator avoidance strategies among zooplankton, notably diel vertical migration, reduced swimming and pigmentation (Bollens et al. 1994; Buskey et al. 2012; Lindegren et al. 2012). Furthermore, small planktonic organisms such as copepods are unlikely able to directly 358 determine the abundance of predators in any given situation, unless they on the basis of strong 359 chemical cues are able to perceive and evaluate the local density of predators and consequently the risk of predation (Heuschele and Selander 2014). Alternatively, the lack of a light effect may 
361 indicate that by selecting for habitats with high food availability (as suggested by the positive Chl $a$ response) the individuals, regardless of species, may increase encounter rates of prey without increasing feeding activity.

In conclusion, our results demonstrate pronounced spatial differences between species in each genus, largely reflected in their vertical abundance distributions. These differences can primarily be explained by different responses to the physical environment, notably in terms of their affinities for habitats with different temperature and salinity conditions. Although we cannot rule out the importance of biotic factors, including species-specific differences in prey preferences and the way species may balance and optimize the trade-off between foraging and predation risk, our results supports pronounced environmental niche separation among closely related copepod species in the North Sea. Despite the relatively limited range of environmental conditions considered in our data set and therefore our inability to fully characterize the entire width of the species environmental niches, our results support the intuitive conclusions that niche separation is more pronounced towards extreme environmental conditions where niche overlap is low (as illustrated by nonoverlapping confidence intervals of the fitted response curves; Fig. 4, 5). In terms of temperature this occurs at $<10-12^{\circ} \mathrm{C}$, while at medium to high temperature the response curves converge and niche separation is weaker, particularly for Calanus. Conversely, niche separation in terms of salinity is pronounced $>35$ psu, while at medium and low salinities the niches and confidence intervals largely overlap for both genera. We expect similar niche separation to occur also in high diversity systems where multiple species (rather than pairs of species) occupy the same genus or other functional grouping. Hence, we argue that environmental niche separation may act as a primary mechanism reducing inter-specific competition and promoting coexistence and the diversity of zooplankton species in marine and limnic ecosystems. 
385 Finally, our study demonstrates the benefit of analysing ecological data using not a single but a 386 suite of different methods, including both traditional regression models and machine learning 387 approaches. By comparing results across methods, the sensitivity of outcomes to the choice of 388 method can formally be assessed. However, we fully acknowledge that applying multiple methods 389 can be challenging, especially since the application of machine learning approaches require a large 390 amount of data for training and cross-validation. Furthermore, machine learning tools are inherently 391 more opaque (e.g., due to the enormous amounts of decision trees produced), at least compared to 392 standard regression models providing readily interpretable parameter estimates. Nevertheless, in 393 our case all approaches (including GAM, RF and GBM) demonstrated similar statistical 394 relationships between species abundances and environmental drivers, hence supporting the 395 robustness of conclusions regarding the existence of environmental niches separation among closely 396 related zooplankton species.

\section{Acknowledgements}

399 ML acknowledge support from the Centre for Ocean Life, a Villum Kann Rasmussen Centre of 400 Excellence funded by the Villum Foundation. MKT received funding from the European Union’s 401 Horizon 2020 research and innovation programme under the Marie Skłodowska-Curie grant 402 agreement TROPHY No. 794264.

\section{References}

405 Angert. A. L., T. E. Huxman, P., Chesson, and D. L. Venable. 2009. Functional tradeoffs determine 406 species coexistence via the storage effect. Proc. Natl. Acad. Sci. 106: 11641-11645. 
Beaugrand, G. 2009. Decadal changes in climate and ecosystems in the North Atlantic Ocean and adjacent seas. Deep-Sea Research Part II: Topical Studies in Oceanography, 56: 656-673. https://doi.org/10.1016/j.dsr2.2008.12.022

Beaugrand, G., K. M. Brander, J. A. Lindley, S. Souissi, and P. C. Reid,. 2003. Plankton effect on cod recruitment in the North Sea. Nature, 426 No, 6967: 661-664.

Beaugrand, G. and P. Helaouët. 2008. Simple procedures to assess and compare the ecological niche of species. Marine Ecology Progress Series, 363: 29-37.

$$
\text { https://doi.org/10.3354/meps07402 }
$$

Ben-David, M., R. T. Bowyer, and J. B. Faro. 1996. Niche separation by mink and river otters: coexistence in a marine environment. Oikos 75: 41-48.

Blenckner, T., M. Llope, C. Möllmann, R. Voss, M. F.. Quaas, M. Casini, M. Lindegren, C. Folke, and N. C. Stenseth. 2015. Climate and fishing steer ecosystem regeneration to uncertain economic futures. Proceedings of the Royal Society B-Biological Sciences. 282: 20142809.

Bollens, S. M., B. W. Frost, and J. R. Cordell. 1994. Chemical, mechanical and visual cues in the vertical migration behaviour of the marine planktonic copepod Acartia hudsonica. J. Plankton Res. 16: 555-564.

Bonnet, D. et al. 2005. An overview of Calanus helgolandicus ecology in European waters. Progress in Oceanography 65: 1-53.

Breiman, L. 2001. Random Forests, Machine Learning 45: 5-32.

Bucklin, A., B.W. Frost, and T. D. Kocher. 1995. Molecular systematics of six Calanus and three Metridia species Calanoida: Copepoda. Mar. Biol. 121: 655.

Buskey, E. J., P. H. Lenz, and D. K. Hartline. 2012. Sensory perception, neurobiology, and behavioural adaptations for predator avoidance in planktonic copepods. Adapt. Behav. 20: 5766. 
431 Chesson, P. 2000. Mechanisms of Maintenance of Species Diversity. Annu. Rev. Ecol. Syst. $432 \quad 31: 343-66$.

433 Connell, J. H. 1980. Diversity and the coevolution of competitors, or the ghost of competition past. $434 \quad$ Oikos, 35: 131-138.

435 Crowder, L. B. 1986. Ecological and morphological shifts in Lake Michigan fishes: glimpses of the 436 ghost of competition past. In: Contemporary studies on fish feeding: the proceedings of 437 GUTSHOP’84 (pp. 147-158). Springer, Dordrecht.

438 Ducklow, H. W., D. K. Steinberg, and K. O. Buesseler. 2001. Upper Ocean Carbon Export and the 439 Biological Pump. Oceanography 14: 50-58.

440 Fleminger, A. and K. Hulsemann. 1977. Geographical range and taxonomic divergence in North 441 Atlantic Calanus C. helgolandicus, C. finmarchicus and C. glacialis. Mar. Biol.40:233-48. 442 Forster, J., A. G. Hirst, and G. Woodward. 2011. Growth and Development Rates Have Different 443 Thermal Responses. The American Naturalist, 178: 668-678.

444 Freund, Y. and R. E. Schapire. 1997. A decision-theoretic generalization of on-line learning and an 445 application to boosting. Journal of computer and system sciences, 55: 119-139.

446 Friedman, J. H. 2001. Greedy function approximation: a gradient boosting machine. Annals of $447 \quad$ statistics, $1189-1232$.

448 Greenwell, B., B. Boehmke, J. Cunningham, and GBM Developers. 2018. gbm: Generalized 449 Boosted Regression Models. R package version 2.1.4. https://CRAN.R-project.org/package=gbm 450 Hardin, G. 1960. The Competitive Exclusion Principle. Science. 131: 1292-1297.

451 Hastie, T. and R. Tibshirani. 1990. Generalized additive models. Chapman and Hall, London. 452 Heath, M. R., J. O. Backhaus, K. Richardson, E. McKenzie, D. Slagstad, J. Dunn, J. G. Fraser, A. 453 Gallego, D. Hainbucher, S. Hay, S. H. Jónasdóttir, H. Madden, J. Mardaljevic, and A. Schacht. 
1999. Climate fluctuations and the spring invasion of the North Sea by Calanus finmarchicus. Fish. Oceanogr. 8: 163-176.

Gallienne, C.P. and D. B. Robins. 2001. Is Oithona the most important copepod in the world's oceans? Journal of Plankton Research, 23: 1421-1432.

Helaouët, P. and G. Beaugrand. 2007. Macroecology of Calanus finmarchicus and C. helgolandicus in the North Atlantic Ocean and adjacent seas. Marine Ecology Progress Series, 345: 147-165.

Heuschele, J. and E. Selander. 2014. The chemical ecology of copepods. Journal of Plankton Research, 364: 895-913.

Hutchinson, G.F. 1957. Cold Spring Harbor Symposia on Quantitative Biology, 22: 415-427.

Johnson, C. L., A.W. Leising, J.A. Runge, E.J.H. Head, P. Pepin, S. Plourde, E.G. Durbin. 2008.

464 Characteristics of Calanus finmarchicus dormancy patterns in the Northwest Atlantic. ICES 465 Journal of Marine Science, 65: 339-350.

Jónasdóttir S.H. and M. Koski. 2011. Biological processes in the North Sea: comparison of Calanus 467 helgolandicus and Calanus finmarchicus vertical distribution and production J. Plankton. Res. $468 \quad 33: 85-103$.

469 Jónasdóttir, S. H., A. W. Visser, K. Richardson, and M. R. Heath. 2015. Seasonal copepod lipid 470 pump promotes carbon sequestration in the deep North Atlantic. Proc. Natl. Acad. Sci. 112: 12122-12126.

Katechakis, A., H. Stibor, U. Sommer, and T. Hansen. 2004. Feeding selectivities and food niche separation of Acartia clausi, Penilia avirostris Crustacea and Doliolum denticulatum Thaliacea in Blanes Bay Catalan Sea, NW Mediterranean. Journal of Plankton Research, 266: 589-603.

Krumhansl, K. A., E.J.H. Head, P. Pepin, S. Plourde, N. R. Record, J.A. Runge, C.L. Johnson. 2018. Environmental drivers of vertical distribution in diapausing Calanus copepods in the Northwest Atlantic. Progress in Oceanography, 162: 202-222, 
Liaw, A. and M. Wiener. 2002. Classification and Regression by randomForest. R News 23: 18-22.

Lindegren, M., D. M. Checkley, T. Rouyer, A. D. MacCall, and N. C. Stenseth. 2013. Climate, fishing, and fluctuations of sardine and anchovy in the California Current. Proceedings of the National Academy of Sciences of the United States of America, 11033: 13672-13677.

Lindegren, M., P. Vigliano and P. A. Nilsson. 2012. Alien Invasions and the Game of Hide and 483 Seek in Patagonia. PLoS ONE, 710.

484 Lindegren M, Ö. Östman and A. Gårdmark. 2012. Interacting bottom-up and top-down effects 485 shape the population dynamics of herring. Ecology, 92: 1407:1413.

MacArthur, R. H. 1958. Population Ecology of Some Warblers of Northeastern Coniferous Forests. Ecology, 394: 599-619.

Mack, R. N., D. Simberloff, W. M. Lonsdale, H. Evans, M. Clout, and F. A. Bazzaz. 2000. Issues 489 in Ecology -Technical Report. Biotic invasions: Causes, epidemiology, global consequences, and

491 McGinty, N., A. D. Barton, N. R. Record, Z. V. Finkel and A. J. Irwin. 2018. Traits structure 492 copepod niches in the North Atlantic and Southern Ocean. Marine Ecological Progress Series: $493 \quad 601,109-126$.

494 Melle, W. and others. 2014. The North Atlantic Ocean as habitat for Calanus finmarchicus: 495 Environmental factors and life history traits. Progress in Oceanography 129: 244-284. 496 Möllmann, C., G. Kornilovs, M. Fetter, F. W. Köster, and H. H. Hinrichsen. 2003. The marine 497 copepod, Pseudocalanus elongatus, as a mediator between climate variability and fisheries in the 498 Central Baltic Sea. Fisheries Oceanography, 124-5: 360-368.

499 Mooney, H. A. and E. E. Cleland. 2001. The evolutionary impact of invasive species. Proceedings 500 of the National Academy of Sciences, 9810: 5446-5451. 
501 Nielsen, T. G. and M. Sabatini. 1996. Role of cyclopoid copepods Oithona spp . Mar. Ecol. Prog. $502 \quad$ Ser. 139: 79-93.

503 Picard, R.R. and R. D. Cook 1984. Cross-validation of regression models. J. Am. Stat. Assoc. 79: $504 \quad 575-583$.

505 Pianka, E. R. 1974. Niche Overlap and Diffuse Competition. Proceedings of the National Academy $506 \quad$ of Sciences, 715: 2141-2145.

507 Poulet, S. A. 1978. Comparison between five coexisting species of marine copepods feeding on 508 naturally occurring particulate matter. Limnology and Oceanography, 236, 1126-1143. 509 R Development Core Team. 2012. R: A Language and Environment for Statistical Computing. R 510 Foundation for Statistical Computing, Vienna, Austria. ISBN: 3-900051-07-0. Available: 511 http://www.R-project.org.

512 Reid, P., C. M. Edwards, G. Beaugrand, M. Skogen, and D. Stevens. 2003. Periodic changes in the 513 zooplankton of the North Sea during the twentieth century linked to oceanic inflow. Fish. $514 \quad$ Oceanogr. 12: 260-269

515 Rykaczewski, R. R. and D. M. Checkley. 2008. Influence of ocean winds on the pelagic ecosystem 516 in upwelling regions. Proceedings of the National Academy of Sciences of the United States of $517 \quad$ America, 1056: 1965-1970.

518 Sabatini, M. and T. Kiørboe. 1994. Egg production, growth and development of the cyclopoid 519 copepod Oithona similis. Journal of Plankton Research, 16: 1329-1351.

520 Schwartzlose, R. A., J. Alheit, A. Bakun, T. R.. Baumgartner, R. Cloete, R. J. M. Crawford, and J. 521 Z. Zuzunaga. 1999. Worldwide large-scale fluctuations of sardine and anchovy populations. 522 South African Journal of Marine Science-Suid-Afrikaanse Tydskrif Vir Seewetenskap, 21: 289$523 \quad 347$. 
Silvertown, J. 2004. Plant coexistence and the niche. Trends in Ecology and Evolution, 1911: 605611.

Steinberg, D. K., S. A. Goldthwait, and D. A. Hansel. 2002. Zooplankton vertical migration and the active transport of dissolved organic and inorganic nitrogen in the Sargasso Sea. Deep. Res. Part I 49: 1-17.

Steiner, C. F., C. E. Cáceres, and S. D. P. Smith. 2007. Resurrecting the Ghost of Competition Past with Dormant Zooplankton Eggs. The American Naturalist, 1693: 416-422.

Takasuka, A., Y. Oozeki, H. Kubota, and S. E. Lluch-Cota. 2008. Contrasting spawning temperature optima: Why are anchovy and sardine regime shifts synchronous across the North Pacific? Progress in Oceanography, 77: 225-232.

van der Lingen, C. D., L. Hutchings, and J. G. Field. 2006. Comparative trophodynamics of anchovy Engraulis encrasicolus and sardine Sardinops sagax in the southern Benguela: are species alternations between small pelagic fish trophodynamically mediated? African Journal of Marine Science, 283-4.

539 lesser sandeel Ammodytes marinus in relation to density dependence and zooplankton $540 \quad$ composition. Mar. Ecol. Prog. Ser. 381: 249-258.

541 Verity, P.G. and V. Smetacek. 1996. Organism life cycles, predation, and the structure of marine 542 pelagic ecosystems. Mar. Ecol. Prog. Ser. 130:277-293.

Visser, A. W., J. Grønning. and S. H. Jónasdóttir. 2017. Calanus hyperboreus and the lipid pump. Limnol. Oceanogr. 62:1155-1165

546 distribution and temperature limitation of fecundity rates in a sac spawning copepod. Marine Biology, 151: 1099-1110. 
548 Wilson R. J., D. C. Speirs, and M. R. Heath. 2015. On the surprising lack of differences between 549 two congeneric calanoid copepod species, Calanus finmarchicus and C. helgolandicus. Progr. $550 \quad$ Oceanogr. 1;134:413-31.

551 Wilson, R.J., M. R. Heath, and D. C. Speirs. 2016. Spatial modeling of Calanus finmarchicus and 552 Calanus helgolandicus: parameter differences explain differences in biogeography. Frontiers in $553 \quad$ Mar. Sci. 3:157.

554 Wood, S.N. 2017. Generalized Additive Models: An Introduction with R 2nd edition. Chapman and $555 \quad$ Hall/CRC.

556 557 558 559 560 561 562 563 564 565 566 567 568 569 570 571 572 573 574 575 576 
577 Table 1. Variable importance of covariates, estimated as the percentage increase in the mean 578 squared error of species abundances in the test data. This is calculated by permuting each covariate 579 in the dataset, while retaining the existing model; an increase in the error after randomisation 580 indicates that the variable was an important predictor within the model. Values without and within 581 parenthesis show the estimates for each species and covariate based on RF and GBM, respectively. 582 C.fin C.hel O.atl O.sim 583 Temperature 44

$53.9(25.6) \quad 46.7(25.6) \quad 54.8(9.8)$

$584 \quad$ Salinity $\quad 41.0(37.8) \quad 43.7(2.9) \quad 55.0(57.1) \quad 25.9(0.1)$

585

$\log ($ Chla $)$

$27.9(2.8) \quad 47.0(6.2) \quad 35.0(2.7) \quad 34.5(3.3)$

586

$\log (\mathrm{PAR}) \quad 25.8(0.7) \quad 32.3(0.2) \quad 36.3(1.4) \quad 15.5(0.1)$

587 stage2

$51.1(17.7) \quad 106.2(57.4) \quad 33.4(12.9) \quad 193.8(78.5)$

588 Transect

$44.7(26.7) \quad 44.5(7.8) \quad 26.8(0.3)$

$39.1(8.2)$

589

590

591

592

593

594

595

596

597

598

599

600

601

602

603

604

605

606

607

608 
609 Table 2. Summary statistics of model performance for each species. The number of observations N, 610 the deviance explained of GAMs in \%, the \% variance explained pseudo- $\mathrm{R}^{2}$ by random forest RF, 611 as well as the mean squared error MSE for each method, including gradient boosting machines 612 GBM.

$\begin{array}{llllllll}613 & & \text { GAM } & & & \text { RF } & & \text { GBM } \\ 614 & \text { Species } & \text { N } & \text { DEV\% } & \text { MSE } & \mathrm{r}^{2} & \text { MSE } & \text { MSE } \\ 615 & \text { C. fin } & 298 & 53.1 & 1.31 & 63.9 & 1.01 & 1.81 \\ 616 & \text { C. hel } & 422 & 35.6 & 1.11 & 56.3 & 0.75 & 1.05 \\ 617 & \text { O. atl } & 310 & 36.8 & 1.71 & 59.5 & 1.08 & 2.12 \\ 618 & \text { O. sim } & 458 & 68.5 & 1.44 & 78.2 & 0.98 & 3.03\end{array}$


636 Figure 1. Map of the North Sea and the position of the transects included in the study: (A) Dogger bank; (B) Buchanon and (C) Hanstholm.

Figure 2. The vertical distribution of $\log$ (Abundance) of (a) Calanus finmarchicus (blue) and Calanus helgolandicus (red), as well as (b) Oithona atlantica (blue) and Oithona similis (red) at each 10 meter depth interval from 5 to 65 meters. The box plots of species are arranged on top of each other at every depth interval for visualisation purposes.

Figure 3. Boxplots of mean square errors (MSE) of model predictions based on 100 randomly selected test data sets for (a) Calanus finmarchicus, (b) Calanus helgolandicus, (c) Oithona atlantica and Oithona similis (d).

Figure 4. The relationships between temperature and the abundance distribution of (a) Calanus (C. finmarchicus, blue; C. helgolandicus, red) and (b) Oithona (O. atlantica, blue; O. similis, red). The left panels show the partial effects of temperature on $\log$ (Abundance) (centred at zero) based on the final GAMs. Solid lines and shaded areas show the mean and 95\% confidence intervals, respectively, and filled circles the observed values for each species. The right panels show the predicted $\log$ (Abundances) (transformed to zero mean and unit variance) based on RFs (solid lines) and GBM (dashed lines).

Figure 5. The statistical relationships between salinity and the abundance distribution of (a) similis, red). The left panels show partial effect plots of log(Abundances) (centred at zero) based on the final GAMs where solid lines and shaded areas show the mean and 95\% confidence intervals, 
respectively and filled circles the observed values for each species. The right panels show the

661 predicted $\log$ (Abundances) (transformed to zero mean and unit variance) based on random forest

662 (solid lines) and GBM (dashed lines).

663

664 Figure 6. The statistical relationships between $\log ($ Chlorophyll a) and $\log ($ abundances) of (a,b)

665 Calanus (C. finmarchicus, blue; C. helgolandicus, red) and (c,d) Oithona (O. atlantica, blue; O.

666 similis, red). The left panels show partial effect plots of log(abundances) (centred at zero) based on

667 the final GAMs where solid lines and shaded areas show the mean and 95\% confidence intervals, 668 respectively and filled circles the observed values for each species. The right panels show the 669 predicted $\log$ (Abundances) (transformed to zero mean and unit variance) based on random forest 670 (solid lines) and GBM (dashed lines).

671

672 Figure 7. Predicted environmental niches of C. finmarchicus (a), C. helgolandicus (b), O. atlantica 673 (c) and $O$. similis (d) across the entire range of observed temperature, salinity and Chlorophyll a 674 values. The size of the dots correspond to the predicted log(Abundances) for each species based on 675 GAMs and illustrate the relative abundance distribution across the 3-D environmental niche space. 676 


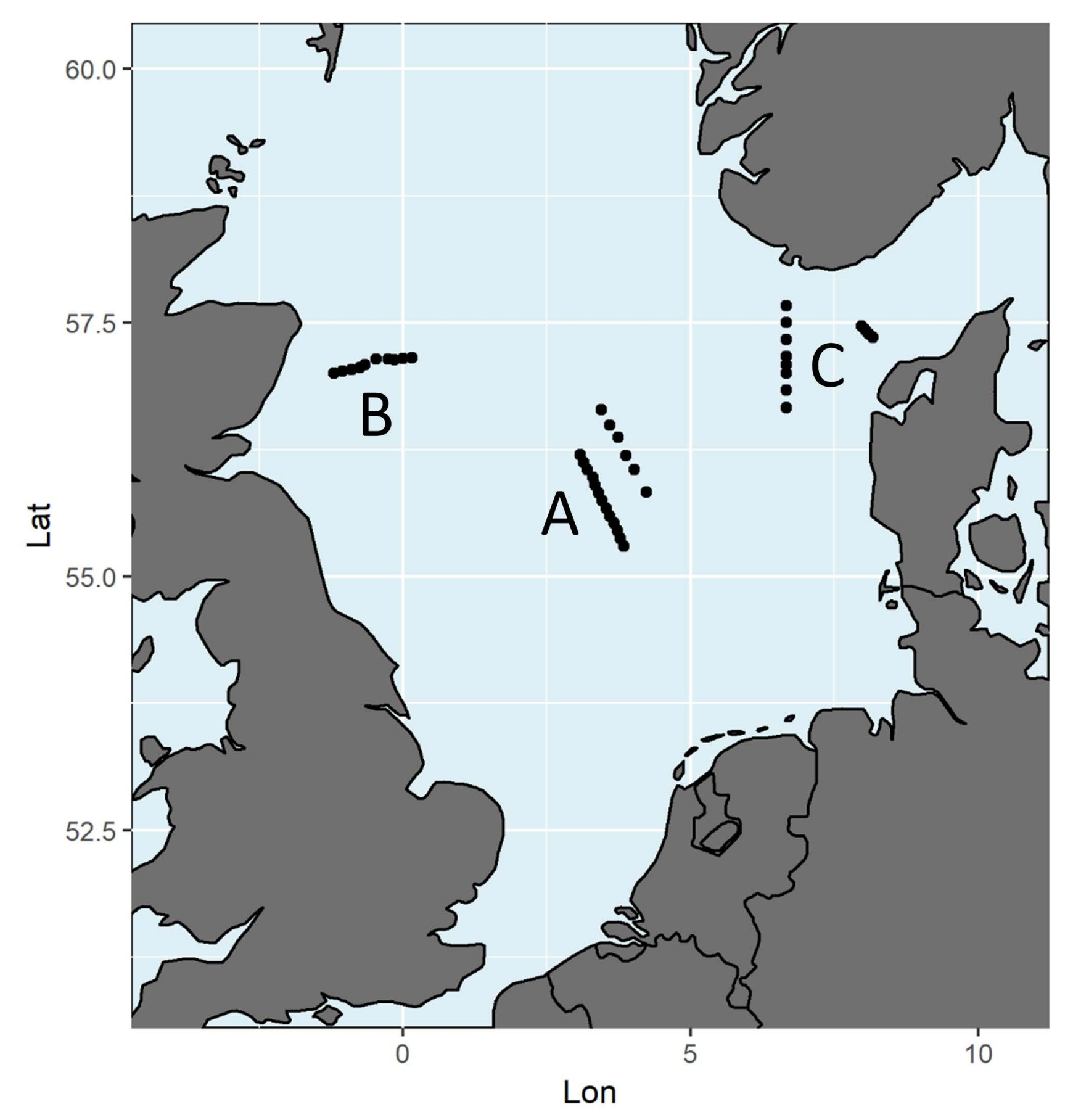



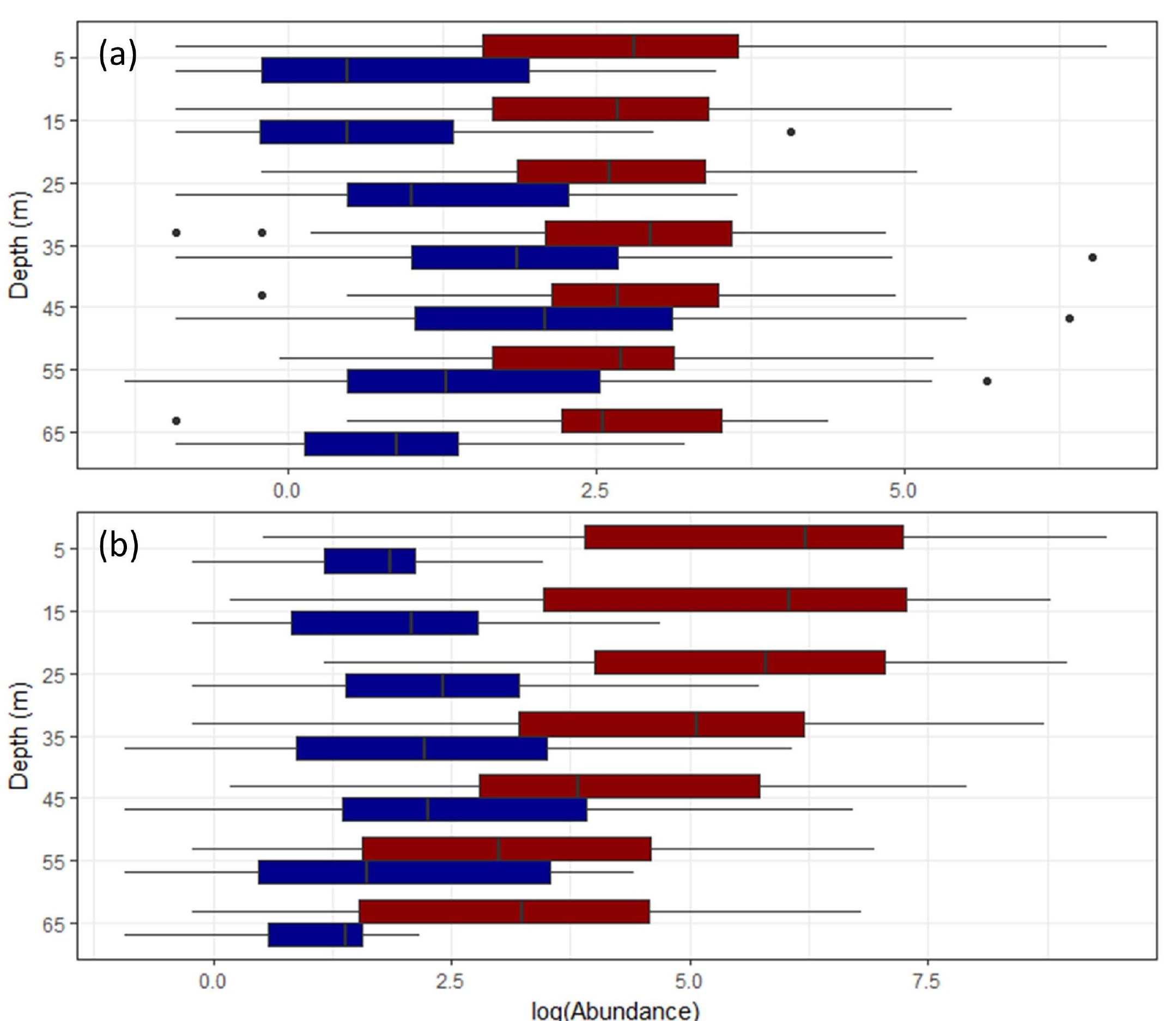

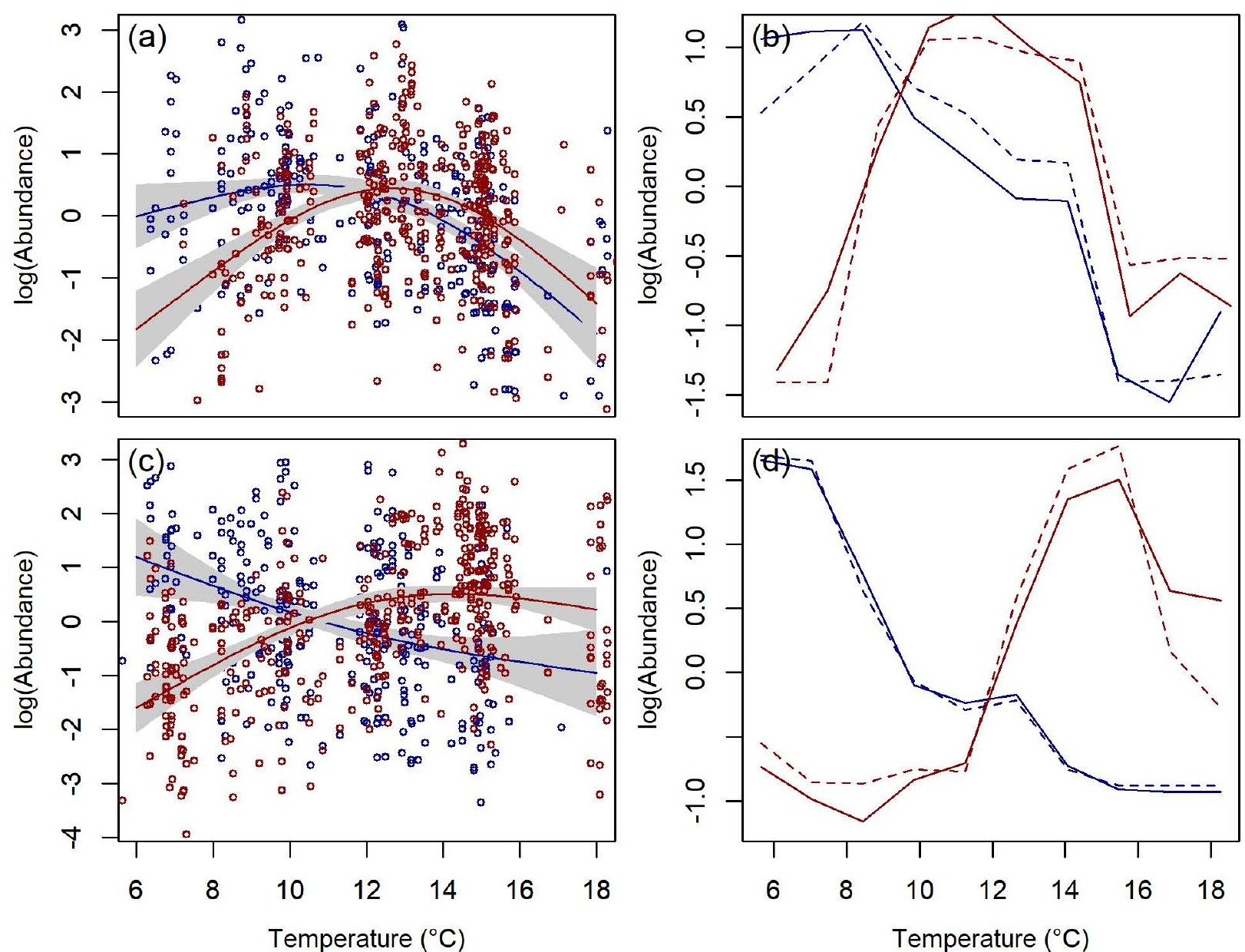

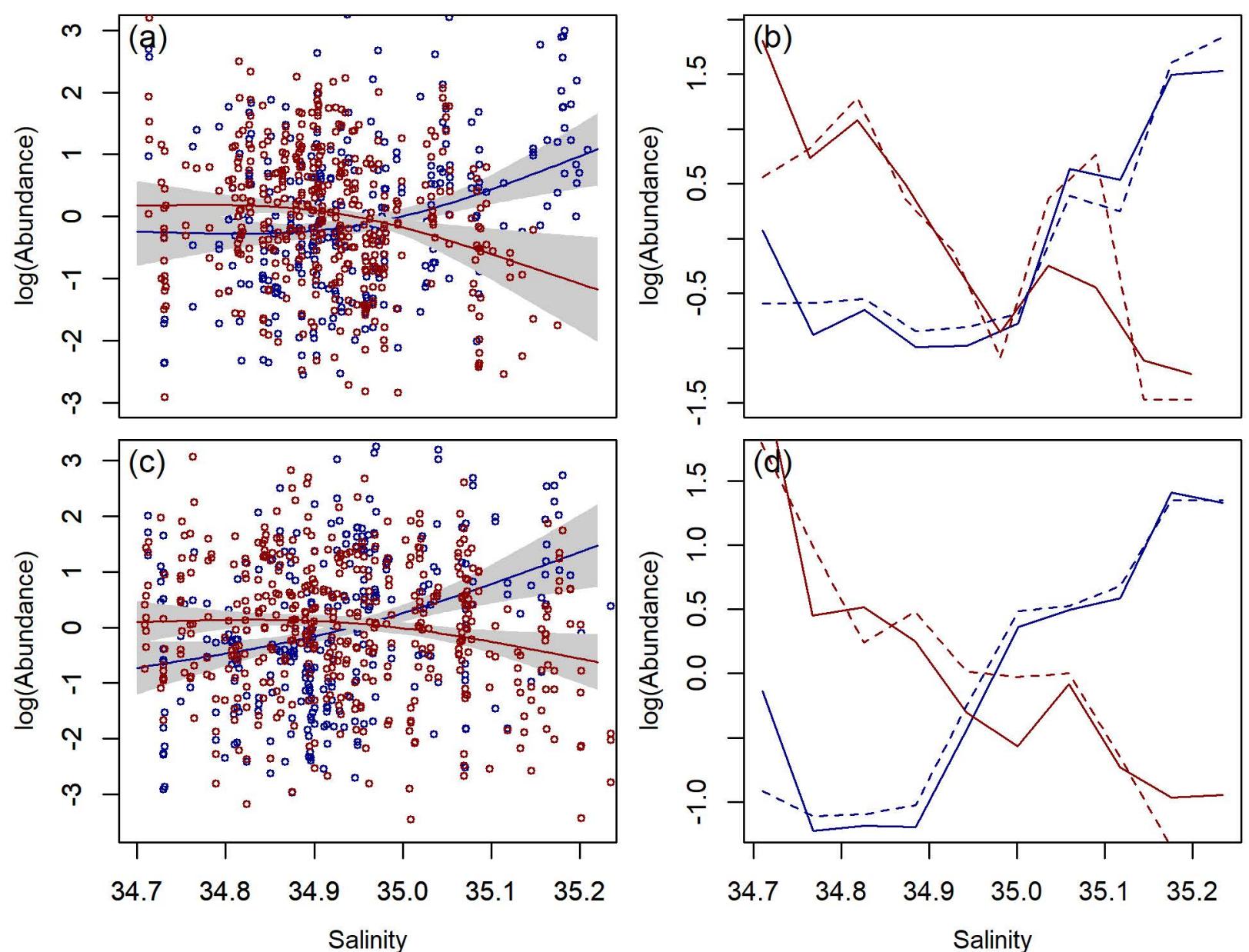

Salinity

Salinity 

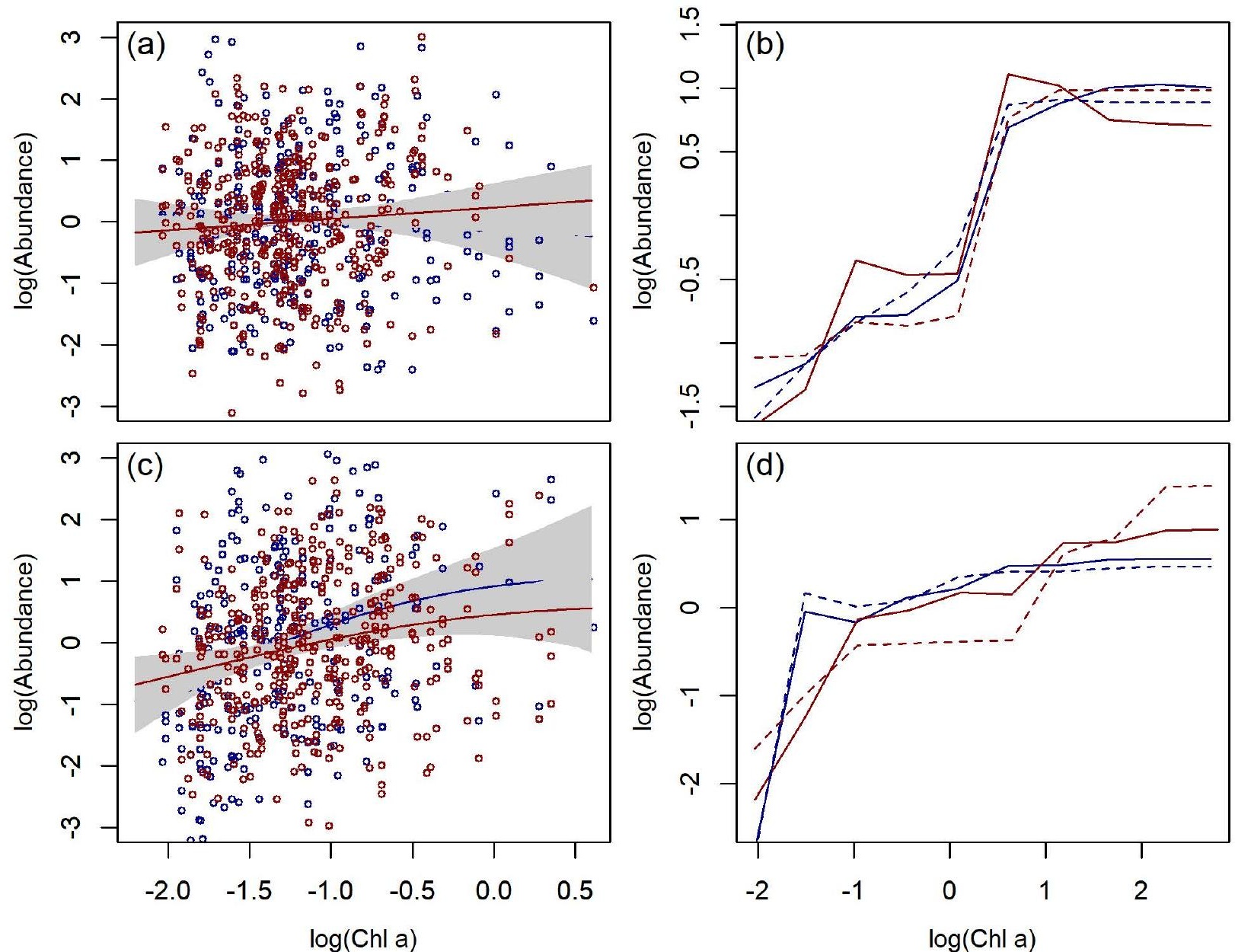

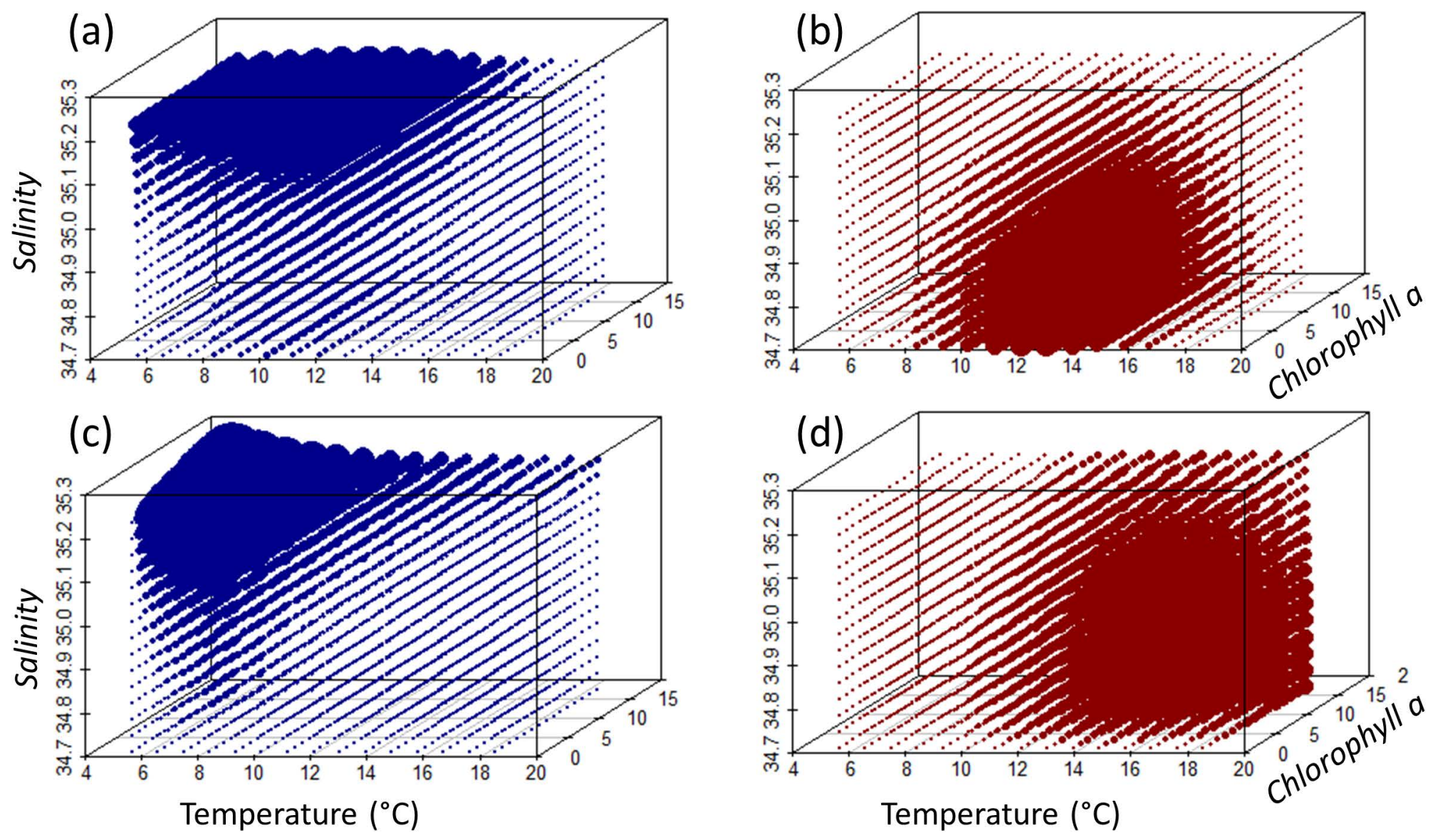
1

3 deviance explained (DEV in \%), the significance of the likelihood ratio test (p) and the number of observations (n) are shown. The final

4 models are highlighted in bold.$$
\text { Response Model }
$$

$6 \quad 1 . \quad \log ($ C.fin $) \sim \alpha+s($ Temp $)+s($ Sal $)+s(\log ($ Chl a $))+s(\log ($ PAR $))+$ transect + stage $\quad 1.4064 \quad 53.8$

2. $\quad \log ($ C.fin $) \sim \alpha+s($ Temp $)+s($ Sal $)+s(\log ($ Chl a $))+$ transect + stage $\quad 1.4009 \quad 53.6 \quad 0.29$

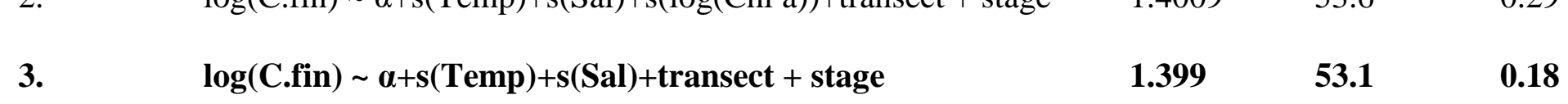


Table S2. Summary statistics of parametric coefficients and smooth terms for the final GAM for $C$.

19 fincmarchicus. edf is the estimated degrees of freedom for the model smooth terms where edf $>1$

20 indicates a non-linear relationship.

21

22

23 (Intercept)

Estimate

Std. Error

t value

$\operatorname{Pr}(>|t|)$

24 Stage:Female

2.1501

0.1599

13.448

$<2 \mathrm{e}-16 * * *$

25 Stage:Male

$$
-0.6296
$$

0.1494

$-4.215$

$3.34 \mathrm{e}-05 * * *$

$-1.6822$

0.2079

$-8.091$

1.67e-14***

26 Transect 2

$-1.0724$

0.1996

$-5.374$

1.59e-07 ***

27 Transect 3

0.2602

0.2706

0.962

0.337

28 Transect 4

1.0428

0.1975

5.280

2.55e-07 ***

29

30

Smooth terms

edf

Ref.df

F

p-value

31 s(Temp)

1.950

1.997

28.479

4.25e-12 ***

$32 \mathrm{~s}(\mathrm{Sal})$

1.802

1.961

7.085

0.00112 **

33 R-sq. $($ adj $)=0.517$ Deviance explained $=53.1 \%$

GCV $=1.399$ Scale est. $=1.3533 n=298$

35

36

37

38

39

40

41

42

43

44

45

46

47 
Table S3. Summary statistics of parametric coefficients and smooth terms for the final GAM for $C$.

49 helgolandicus. edf is the estimated degrees of freedom for the model smooth terms where edf $>1$

50 indicates a non-linear relationship.

51

52

53 (Intercept)

Estimate

Std. Error t value

$\operatorname{Pr}(>|t|)$

54 Stage:Female

2.58782

$0.11818 \quad 21.897$

$<2 \mathrm{e}-16 * * *$

55 Stage:Male

0.02966

0.12521

0.237

0.812894

56 Transect 2

$-1.41341$

0.13349

$-10.588$

$<2 \mathrm{e}-16 * * *$

0.38518

0.14776

2.607

$0.009470 * *$

57 Transect 3

1.06772

0.27266

3.916

$0.000105 * * *$

58 Transect 4

0.80616

0.21149

3.812

$0.000159 * * *$

59

60

Smooth terms

edf

Ref.df

F

p-value

$61 \mathrm{~s}$ (Temp)

1.992

2.000

20.535

3e-09***

62

$\mathrm{s}(\mathrm{Sal})$

1.763

1.944

4.646

$0.011 *$

63

R-sq. $($ adj $)=0.343$ Deviance explained $=35.6 \%$

64

GCV $=1.1641$ Scale est. $=1.1372 n=422$

65

66

67

68

69

70

71

72

73

74

75

76

77

78 
79 Table S4. Summary statistics of parametric coefficients and smooth terms for the final GAM for $O$.

80 atlantica. edf is the estimated degrees of freedom for the model smooth terms where edf $>1$

81 indicates a non-linear relationship.

82 Parametric coefficients Estimate

Std. Error $t$ value $\operatorname{Pr}(>|t|)$

83 (Intercept)

3.11378

0.21960

14.180

$<2 \mathrm{e}-16 * * *$

84 Stage:Female

$-0.63899$

0.19228

$-3.323$

$0.001001 * *$

85 Stage:Male

$-0.72853$

0.19794

$-3.681$

$0.000276 * * *$

86 Transect 2

$-0.39187$

0.20688

$-1.894$

0.059168 .

87 Transect 3

$-0.02362$

0.30985

$-0.076$

0.939274

88 Transect 4

$-1.11610$

0.41270

$-2.704$

$0.007236 * *$

89 Transect 5

$-2.32136$

$1.25341-1.852$

0.065008 .

90

91 Smooth terms

edf

\section{Ref.df}

F

p-value

$92 \mathrm{~s}$ (Temp)

1.447

1.694

8.238

$0.000938 * * *$

$93 \mathrm{~s}(\mathrm{Sal})$

1.590

1.832

11.476

4.17e-05 ***

$94 \mathrm{~s}(\log (\mathrm{Chl} \mathrm{a}))$

1.413

1.654

5.339

$0.009515 * *$

95 R-sq.(adj) $=0.346$ Deviance explained $=36.8 \%$

$96 \mathrm{GCV}=1.8472$ Scale est. $=1.7789 \mathrm{n}=310$

97

98

99

100

101

102

103

104

105

106

107

108 
109 Table S5. Summary statistics of parametric coefficients and smooth terms for the final GAM for $O$.

110 similis. edf is the estimated degrees of freedom for the model smooth terms where edf $>1$ indicates a 111 non-linear relationship.

112

113 Parametric coefficients Estimate Std. Error t value $\operatorname{Pr}(>|t|)$

114 (Intercept)

$6.9631 \quad 0.2350 \quad 29.629<2 \mathrm{e}-16 * * *$

115 Stage:Female

$-0.5670$

0.1861

$-3.046$

$0.00246 * *$

116 Stage:Male

$-3.3366$

0.1868

$-17.864$

$<2 \mathrm{e}-16 * * *$

117 Transect 2

$-1.4363$

0.1800

$-7.979$

$1.26 \mathrm{e}-14 * * *$

118 Transect 3

$-0.7095$

0.3046

$-2.329$

$0.02029 *$

119 Transect 4

$-0.3553$

0.2060

$-1.725$

0.08530 .

120 Transect 5

0.4899

0.6371

0.769

0.44231

121

\section{Smooth terms}

edf

Ref.df

F

p-value

123 s(Temp)

1.948

1.997

25.493

3.15e-11***

$124 \mathrm{~s}(\mathrm{Sal})$

1.696

1.908

3.046

0.051147 .

$125 \mathrm{~s}(\log$ (Chla))

1.000

1.000

12.549

$0.000437 * * *$

126 R-sq. $($ adj $)=0.677$ Deviance explained $=68.5 \%$

$127 \mathrm{GCV}=1.5158$ Scale est. $=1.4772 \mathrm{n}=458$

128

129

130

131

132

133

134

135

136

137

138

139

140 
142 Figure S1. Vertical profiles of Calanus (left column) and Oithona (right column) species for five 143 selected field series. The size of symbols show the relative abundances of given species (absolute 144 abundances can differ for species in same graph) while type and color indicate the species where $145 \mathrm{red} /$ square represents $C$. finmarchicus and $O$. atlantica and blue represents $C$. helgolandicus and $O$. 146 similis. The contour lines show levels of salinity while the solid grey area indicates the bottom. 147 Depth (m), distance indicated by station number, with $10 \mathrm{~nm}$ between stations. 

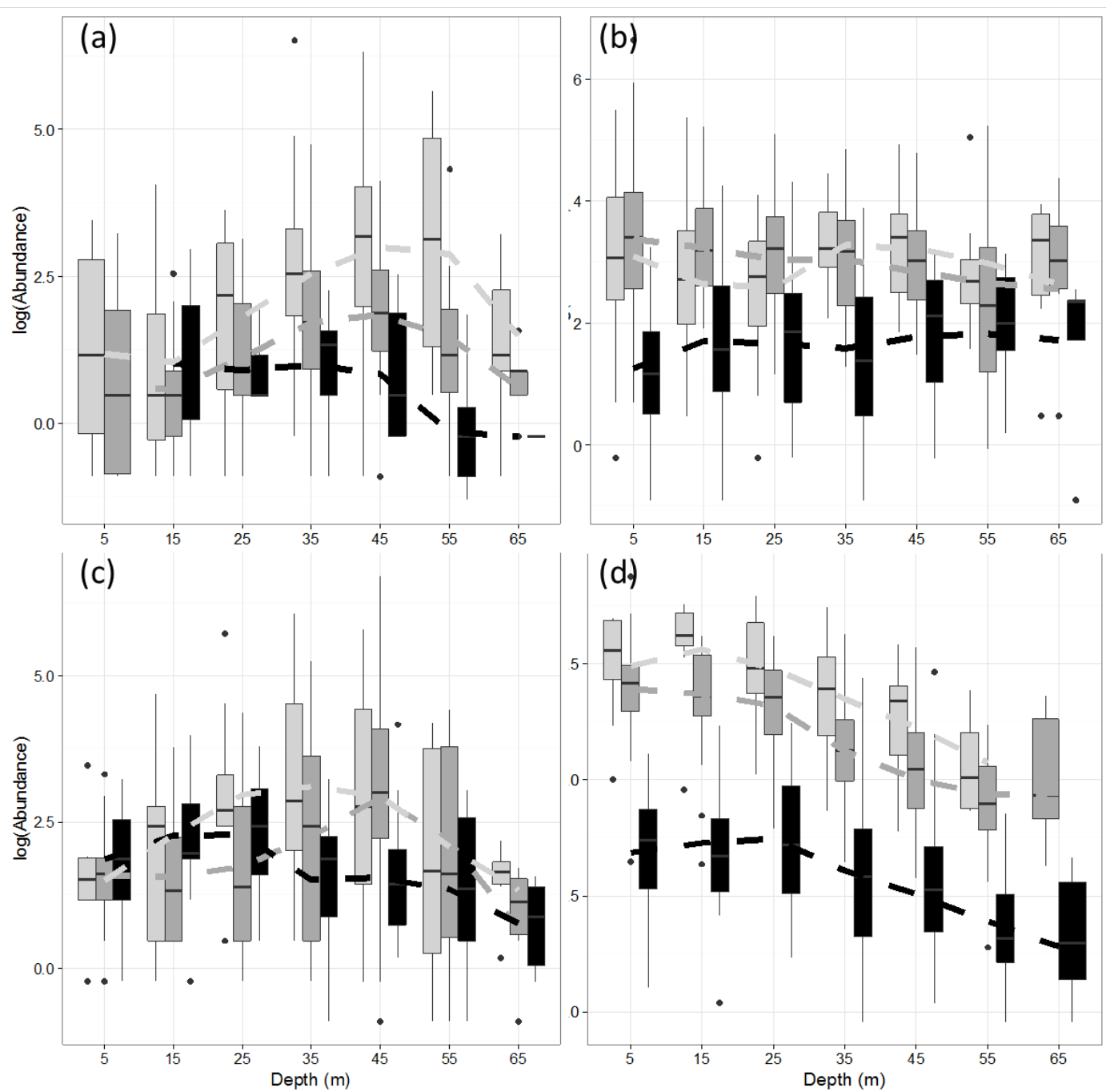

(d)

Figure S2. The vertical distribution of $\log$ (Abundances) of (a) Calanus finmarchicus, (b) Calanus helgolandicus, (c) Oithona atlantica and (d) Oithona similis by each life-stage corresponding to

153 adult females (light grey) and males (dark grey) and juveniles(i.e., copepodites, black). Dashed 154 smooth lines illustrate the main vertical distribution for each species and life-stage. 


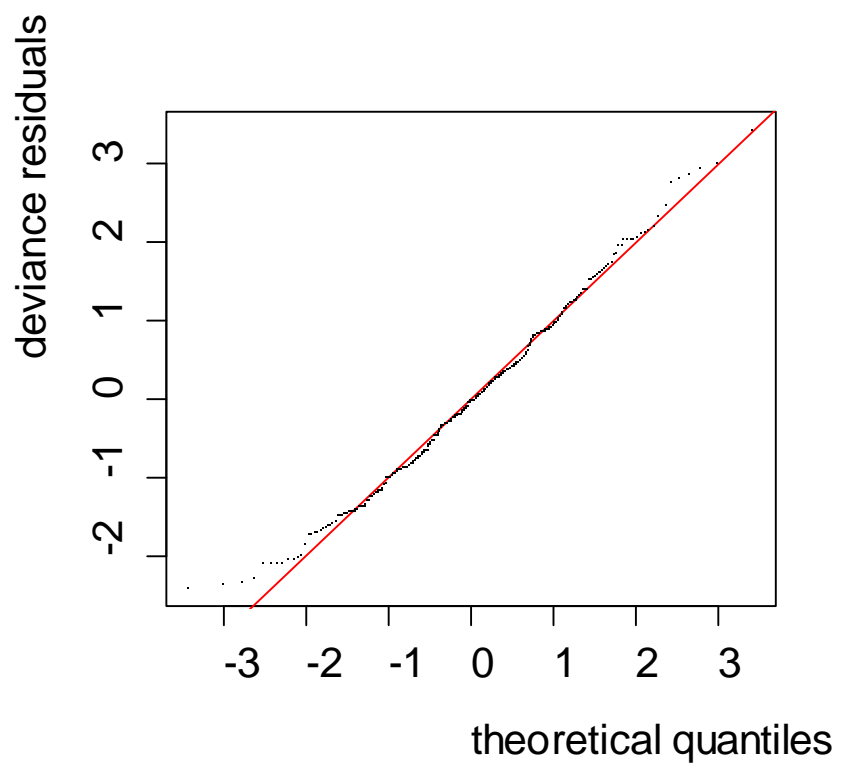

Resids vs. linę

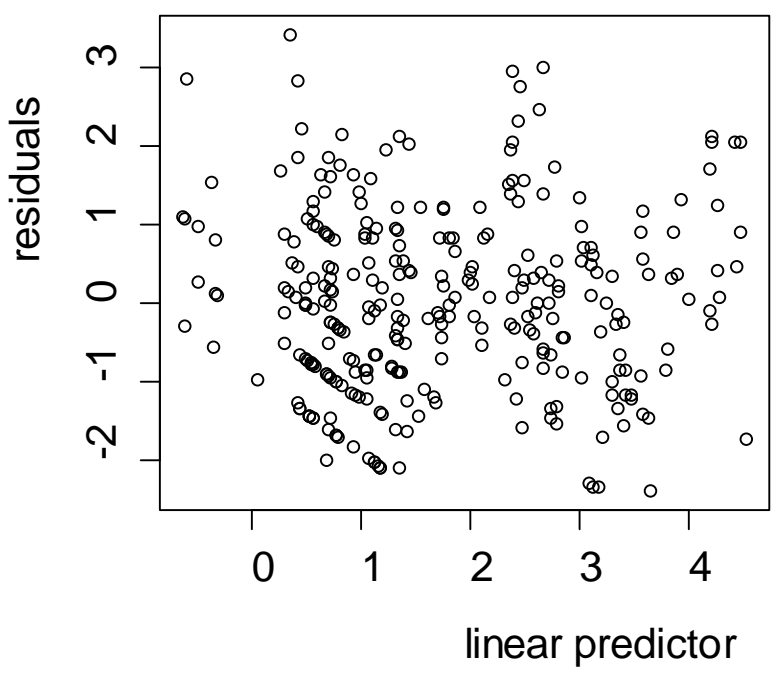

Histogram of re

Response vs. $F$
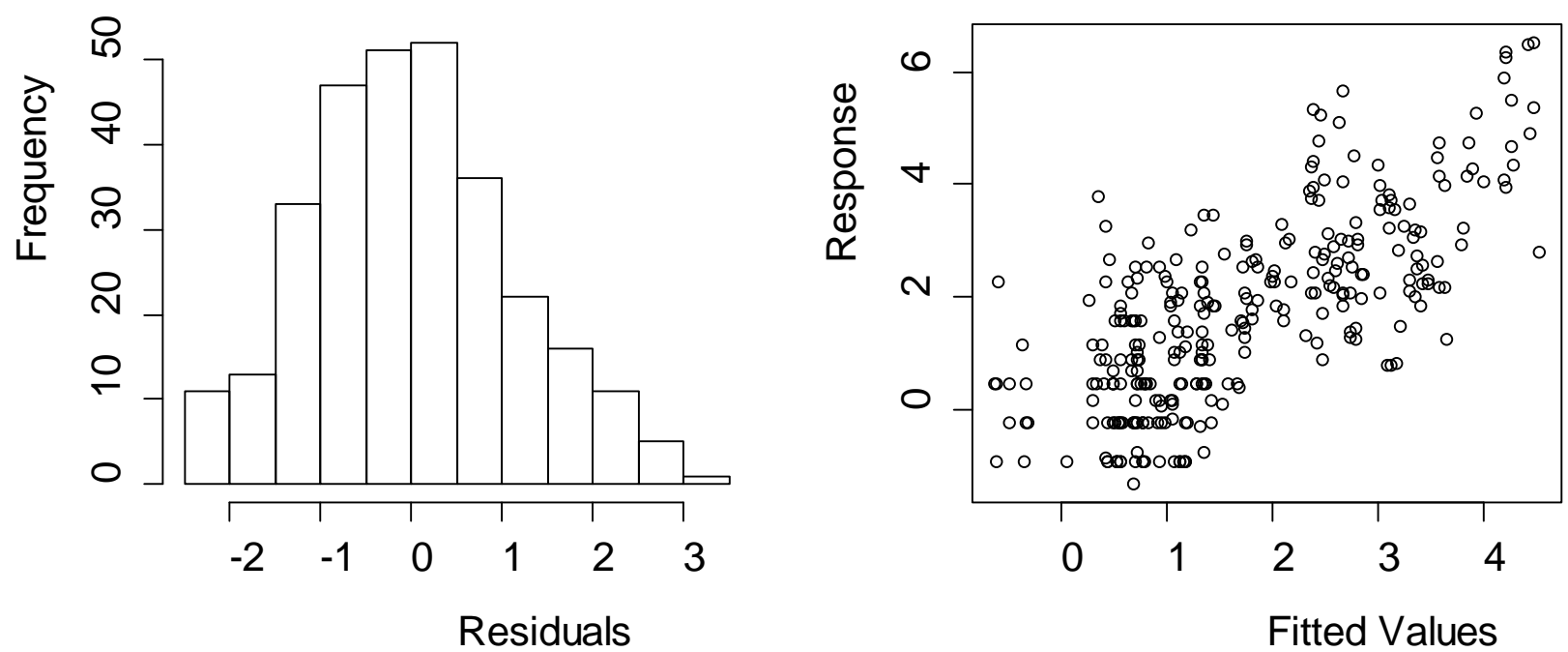

Fitted Values

158 Figure S3. Residual diagnostics for the final GAM for C. fincmarchicus. The axis-labels referring 159 to fitted values, response and linear predictor are in the unit of log(abundances). 


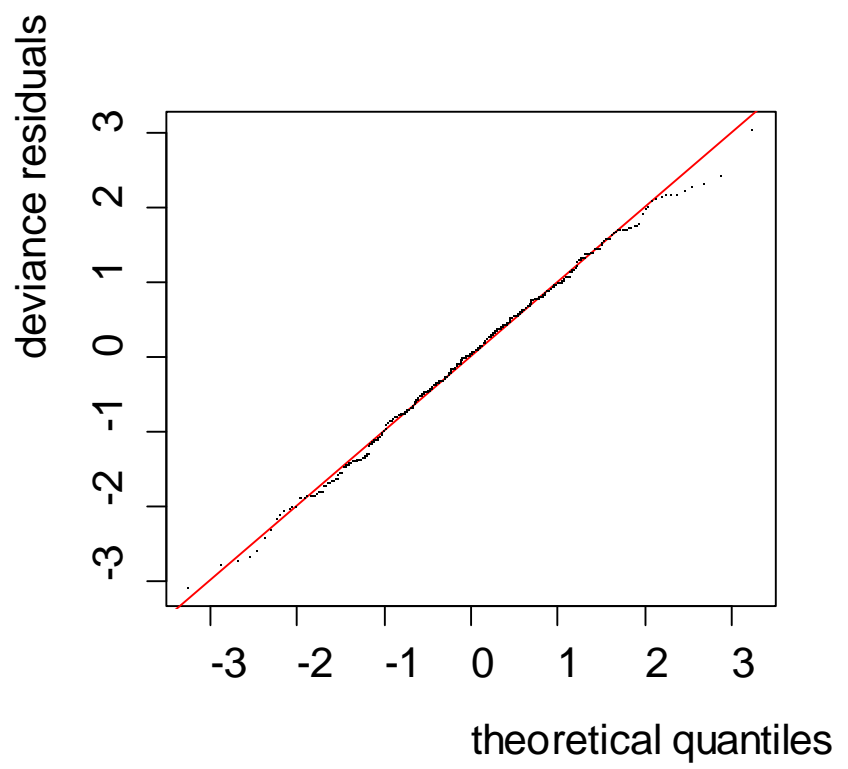

Resids vs. linei
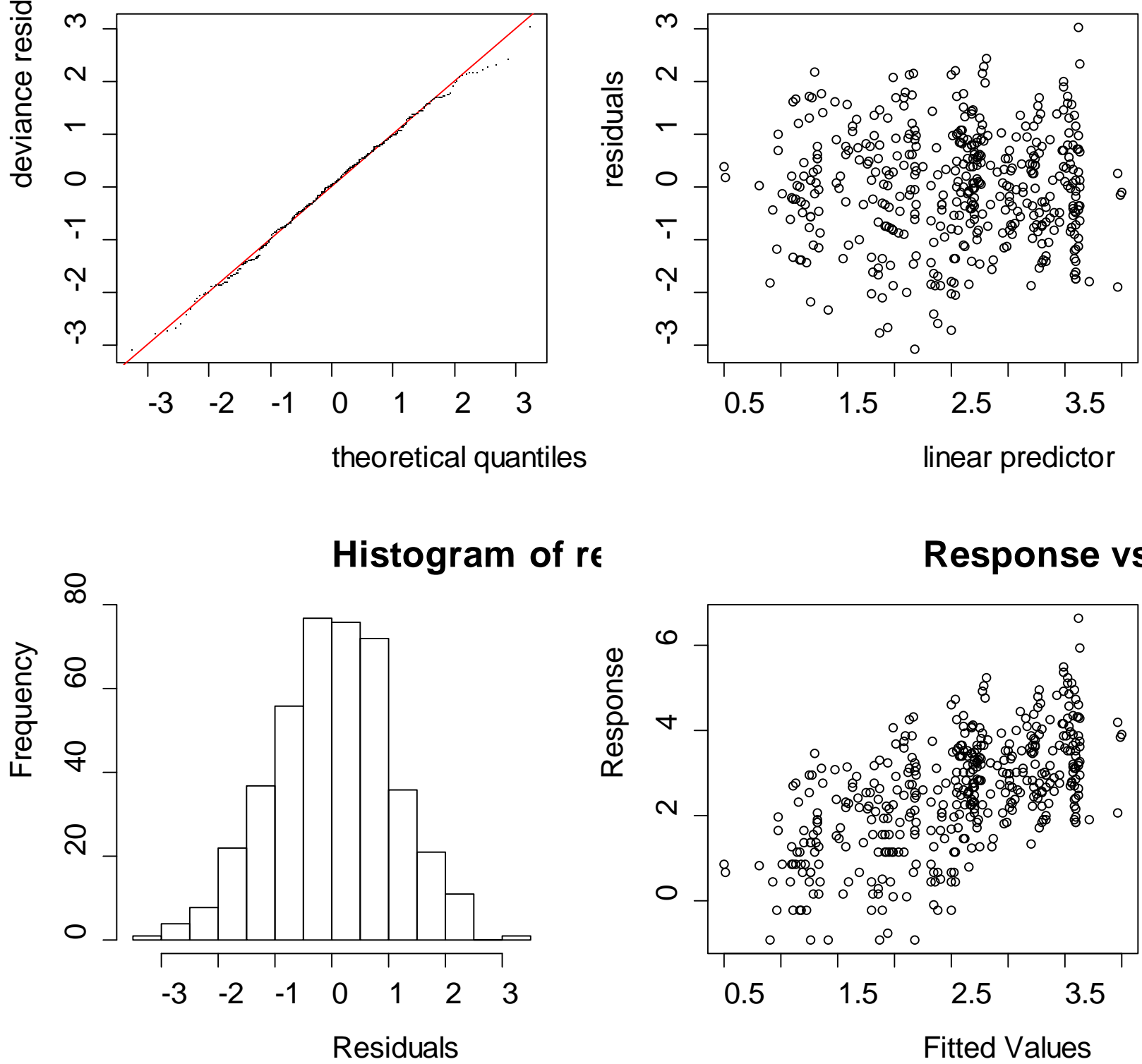

Response vs. F

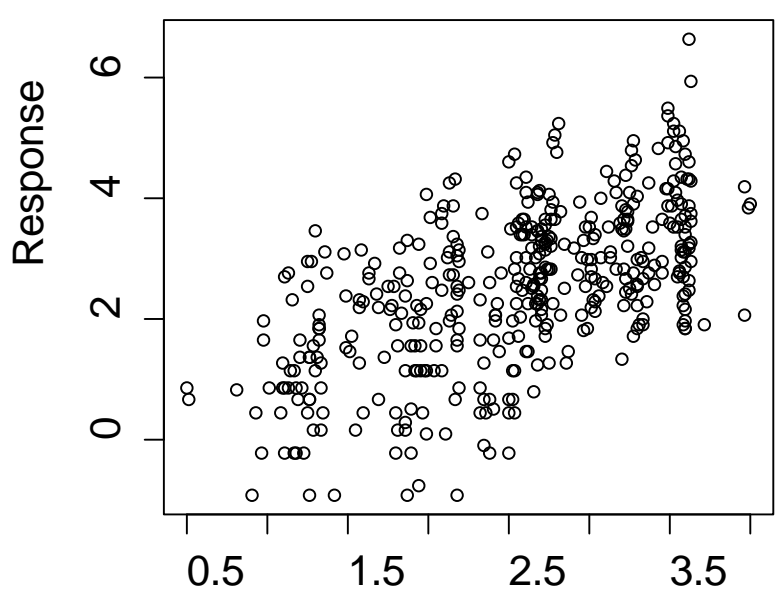

Fitted Values

161 Figure S4. Residual diagnostics for the final GAM for C. helgolandicus. The axis-labels referring 162 to fitted values, response and linear predictor are in the unit of $\log$ (abundances). 


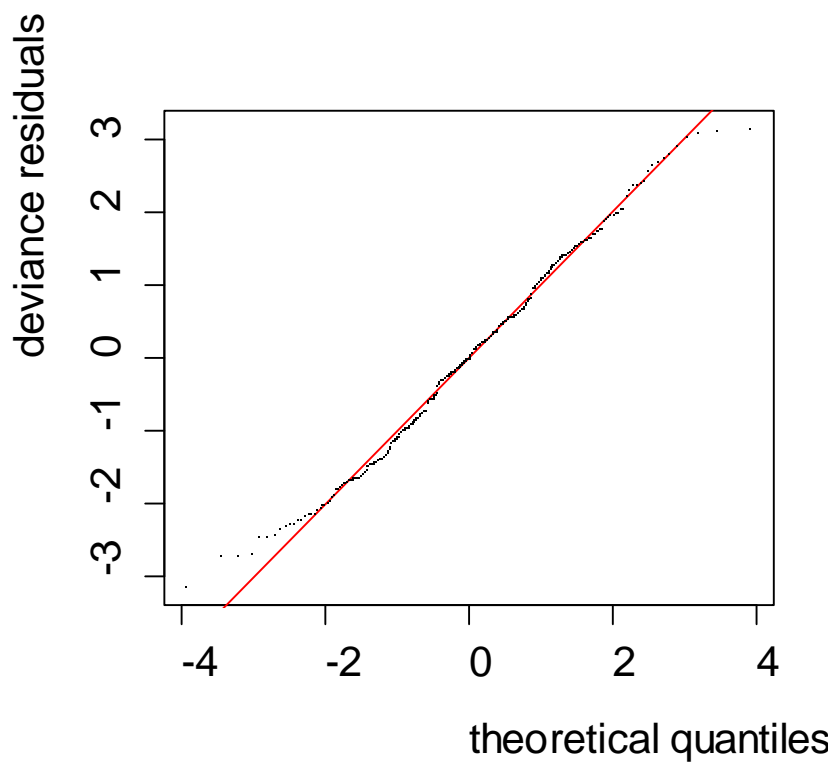

Resids vs. line๕

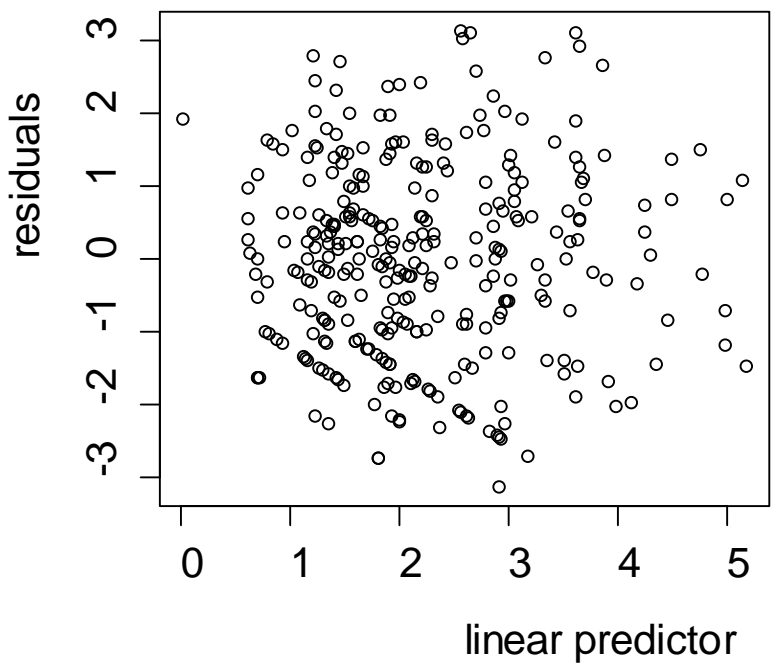

Histogram of re

Response vs. F
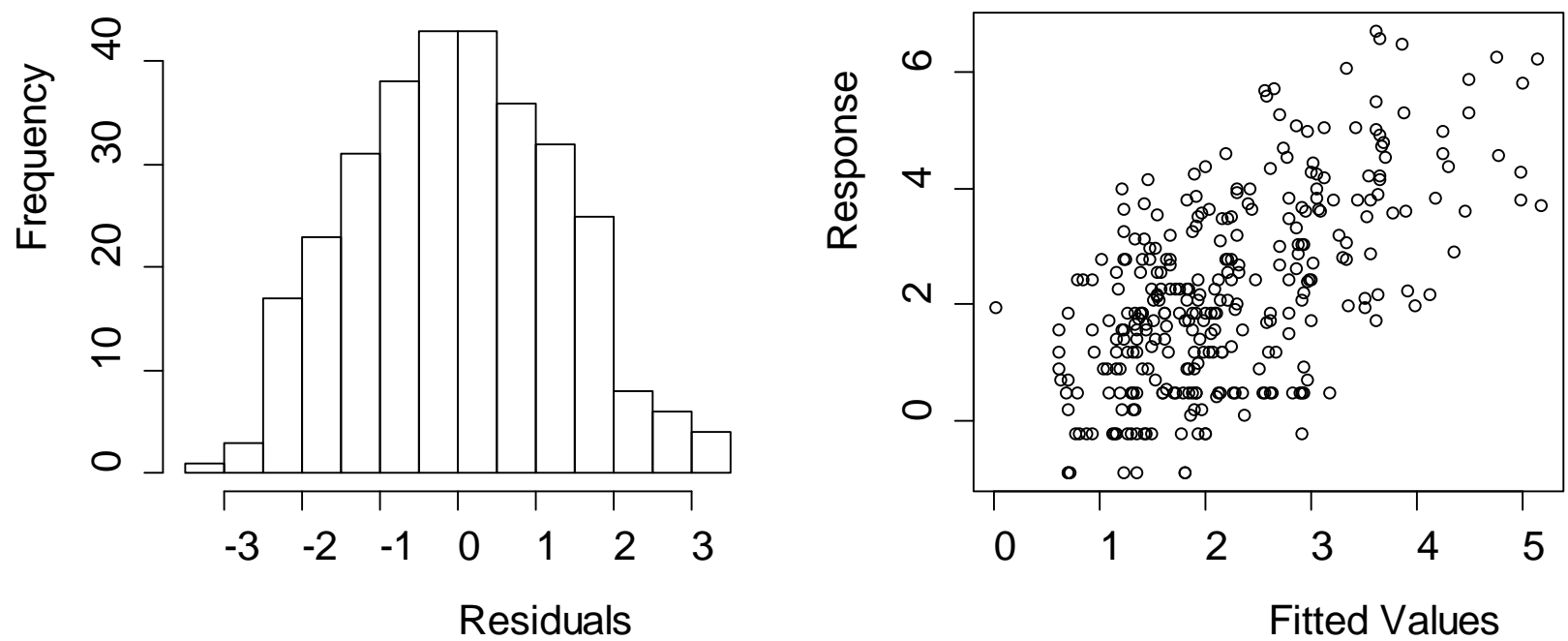

Fitted Values

164

165 Figure S5. Residual diagnostics for the final GAM for O. atlantica. The axis-labels referring to

166 fitted values, response and linear predictor are in the unit of log(abundances). 


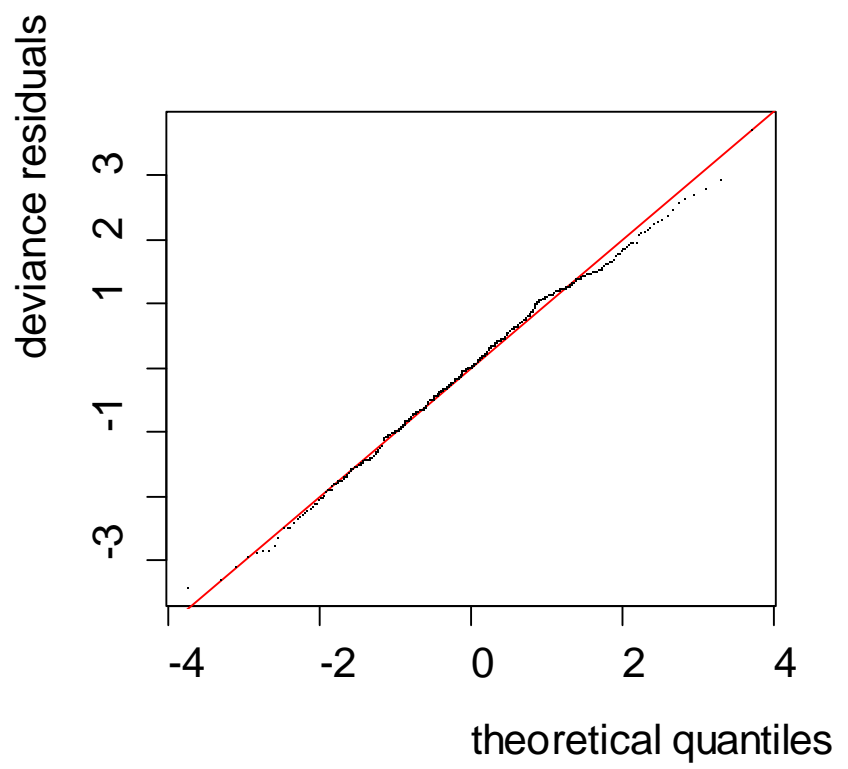

Resids vs. line๕

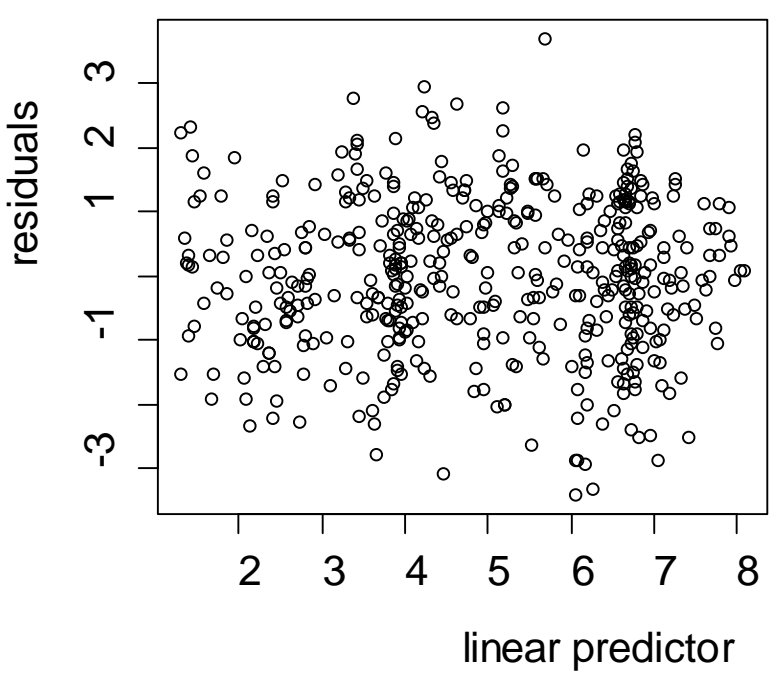

Histogram of re

Response vs. F
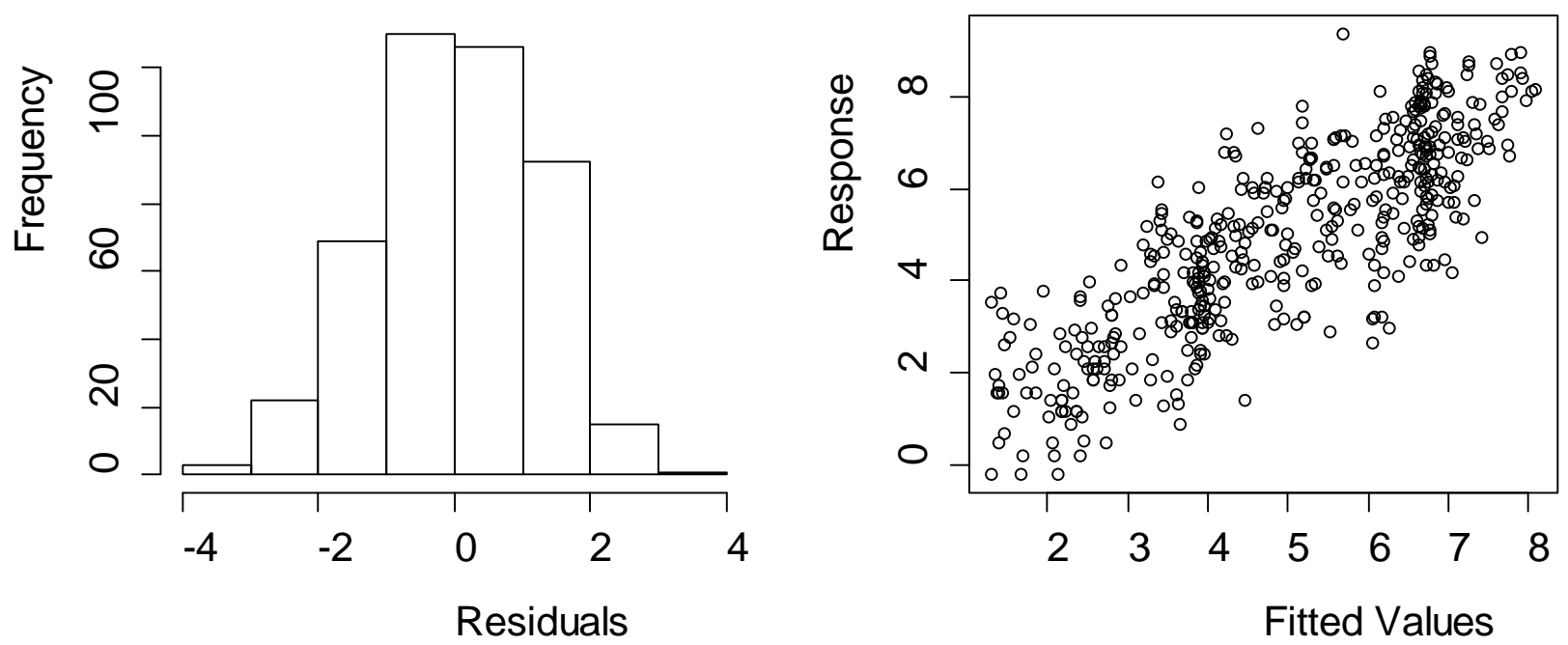

169 Figure S6. Residual diagnostics for the final GAM for $O$. similis. The axis-labels referring to fitted 170 values, response and linear predictor are in the unit of $\log$ (abundances). 